\title{
"Enjambres" y "nubarrones" en el campo oaxaqueño: las plagas de langosta de 1802 y 1853
}

\author{
Luis Alberto Arrioja Díaz Viruell* \\ EL COLEGIO DE MICHOACÁN
}

Los enjambres de langosta han producido otros infinitos: ya saltan estos nuevos a los sembrados y los devoran, como si les lloviese fuego...

Informe del subdelegado de Teotitlán del Valle (1804)

La langosta, por la naturaleza característica de su invasión, debiera tratarse como al enemigo que pone a la patria en peligro, pues si este extermina las poblaciones por el acero y el fuego, el insecto amenaza la vida de los pueblos arrancándoles súbitamente todo medio de alimentación.

Dictamen sobre la langosta presentado por la Escuela Nacional de Agricultura (1856)

Este trabajo intenta reflexionar sobre los factores que posibilitaron el surgimiento y desarrollo de dos plagas de langosta en el territorio del actual estado de Oaxaca. Con esto en mente, se examinan los daños agrícolas que causaron estos insectos y se discuten las acciones desplegadas - por autoridades y pueblos indios- para combatirlos. Simultáneamente se discuten los avances o retrocesos que experimentó el conocimiento respecto a dichas plagas en el siglo XIX.

(Plagas, langosta, pueblos de indios, sementeras, Oaxaca)

\section{INTRODUCCIÓN ${ }^{\mathrm{I}}$}

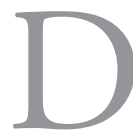

esde hace algunas décadas, la historiografía sobre el México colonial y republicano ha utilizado sistemáticamente el concepto de plaga para referirse a la irrupción de insectos

*larrioja@colmich.edu.mx

${ }^{1}$ Quiero agradecer los comentarios de Antonio Escobar Ohmstede, Thomas Calvo y Chantal Cramaussel a una versión preliminar de este trabajo. Agradezco también al FOMIX CONACYT-Gobierno del Estado de Oaxaca por el apoyo brindado para la realización de este artículo mediante el proyecto M0036-2010-C01-144258 "Liberalismo, pueblos de indios y afromestizos, y tierras comunes: Oaxaca, 1742-1925”. 
que actúan sobre las especies vegetales causando afectaciones en sus cadenas tróficas, en su equilibrio ecológico y en sus ciclos de vida. Obviamente, el concepto también ha sido relacionado con sociedades indígenas afectadas por la irrupción de dichas especies en sus campos de labranza. Si bien es cierto que las plagas han sido registradas por los estragos naturales que generan, también es verdad que llenan los anales por su formación y evolución azarosa. Basta recordar los testimonios bíblicos de la octava plaga que azotó Egipto, la cual se compuso de langostas que aparecieron una "mañana y cubrieron súbitamente toda la tierra [...], eran tantas que se oscureció el día y no se veía nada. Se comieron toda la hierba de la tierra, todos los frutos de los árboles [...] y no quedo nada verde". ${ }^{2}$ Otras fuentes antiguas, como las Etimologías de San Isidoro de Sevilla, el Liber de Natura Rerum de Thomas de Cantimpré y el Hayat al-Hayawan de Muhammad Ibn Musa Al-Damiri también registraron la aparición repentina y los trastornos que causaron las plagas en las superficies agrícolas. ${ }^{3}$ Inclusive, los primeros cronistas de Indias - como fray Bernardino de Sahagún, Gonzalo Fernández de Oviedo y Bernal Díaz del Castillo- hicieron lo propio y señalaron la desolación que dejaban los enjambres de artrópodos a su paso por los campos y los pueblos nativos. ${ }^{4}$ Dado esto, no es casualidad que una amplia documentación colonial y republicana registre cómo, ante el ataque de dichas plagas, la cubierta vegetal experimentaba la degradación, los hombres padecían la escasez de alimento y las autoridades enfrentaban una merma en la captación de impuestos. ${ }^{5}$

2 Sagrada Biblia, versión directa de las lenguas originales por Eloino Nacar Fuster, Madrid, Editorial Católica, 1947, Éxodo, libro 10, pp. 13-15.

${ }^{3}$ San Isidoro de Sevilla, Etimologías, 2 vols., Edición facsimilar, Madrid, Editorial Católica, 1982-1983; Thomas de Cantimpré, Liber de natura rerum..., en Codex Grantensis c-67 (versión digital), Granada, Biblioteca Universitaria de Granada, 2002; Muhammad Ibn Musa Al-Damiri, Hayat al-Hayawan...en Eugene Daumas, Itineraire d'une caravane du Sahara us Pays des Negres, París, 1848.

${ }^{4}$ Fray Bernardino de Sahagún, Historia General de las Cosas de Nueva España..., México, Editorial Porrúa, 1990, 299; Gonzalo Fernández de Oviedo, Historia generaly natural de las indias..., vol. II, Madrid, Biblioteca de Autores Espańoles, 1959, 84-85; Bernal Díaz del Castillo, Historia verdadera de la conquista de la Nueva España..., México, Editorial Porrúa, 1963, 43.

${ }^{5}$ Lo anterior puede observarse con detalle en Virginia García Acosta, América Moli- 
La concordancia que se observa entre los apuros que causaron estas plagas en Europa y América no es accidental, pues en las sociedades agrarias una cosecha afectada no fue solamente un problema económico, sino un suceso que perturbó la estructura social. Es decir, cuando los alimentos escasearon también afloró el hambre y la enfermedad. De ahí, entonces, que el miedo y la inseguridad se apoderara de las sociedades. Diversas fuentes revelan que la presencia de estas plagas varió espacialmente pero no temporalmente. Su presencia fue tan constante que -durante los siglos XVIII y XIX- diversos hombres trataron de comprender su incidencia y propagación; inclusive, tanto autoridades coloniales como republicanas no dudaron en legislar al respecto e instar a la población para exterminarlas.

Lo interesante de las plagas de langosta es que, pese a su influjo en la estructura agraria, la historiografía mexicana las ha referido como uno de tantos factores que provocaron las crisis agrícolas de los siglos XVIII y XIX. ${ }^{6}$ Obviamente, este enfoque ha motivado - por una parte-

na del Villar y Juan Manuel Pérez Zevallos, Desastres agrícolas en México. Catálogo histórico. Tomo I. Época prehispánica y colonial (958-1822), México, Ciesas, Fondo de Cultura Económica, 2003; Antonio Escobar Ohmstede, Desastres agrícolas en México. Catálogo histórico. Tomo II. Siglo XIX, México, Ciesas, Fondo de Cultura Económica, 2004.

${ }^{6}$ La inmensa mayoría de los trabajos que abordan las crisis agrícolas en México durante los siglos XVIII y XIX se limitan a mencionar los estragos de las plagas de langosta sin detenerse en su naturaleza. Muy probablemente, esto tiene que ver con la preferencia historiográfica para examinar las secuelas económicas y sociales que provocaron los desastres naturales y los fenómenos atípicos de la naturaleza, tales como las plagas y las epizootias. Véase: Enrique Florescano, Precios del maiz y crisis agrícolas en México (1708-1810), México, El Colegio de México, 1969, 130-134, 145-148; Enrique Florescano y Susan Swan, Breve historia de la sequía en México, Xalapa, Universidad Veracruzana, 1995, 142 165; Rodolfo Pastor, "Introducción", en Enrique Florescano (comp.), Fuentes para la historia de la crisis agrícola de 1785-1786, vol. 1, México, Archivo general de la Nación, 1981, 15-16; Gerardo Sánchez Díaz, "Crisis agrícolas y abastecimiento de granos en Michoacán, 1880-1910”, en Gail Mummert, coord., Almacenamiento de productos agropecuarios en México, México, El Colegio de Michoacán, Almacenes Nacionales de Depósito, S. A., 1987, 137-139; Pedro Bracamonte y Sosa, Amos y sirvientes. Las haciendas de Yucatán, 1789-1860, Mérida, Universidad Autónoma de Yucatán, 1993, pp. 231-232; Sergio Quezada, “Epidemias, plagas y hambres en Yucatán, México (1520-1700)”, en Revista Biomed, núm. 6, 1995, 238-242; María Isabel Campos Goenaga, "Yucatán: entre el privilegio de la Corona y el azote de la naturaleza”, en Cuicuilco, vol. 10, núm. 29, septiembre-diciembre, 2003; Alejandra García Quintanilla, "Saak y el retorno del fin del mundo. La plaga de langosta en las profecías del Katun 13 Ahau”, en Ancient Mesoamerica, vol. 16, núm. 2, 2005, 327-344; Leticia Reina, "Poblamiento y epidemias en el Istmo 
que el fenómeno mismo se confunda con los resultados que acarreó $\mathrm{y}$-por otra parte- que exista un amplio desconocimiento sobre las condiciones que los originaron, los contextos en que se desarrollaron y las respuestas sociales al respecto. En contraste, el enfoque que asumo para estudiar este fenómeno natural mantiene la primacía de que toda plaga cobró sentido en la medida que existían - por un ladofuentes confiables de alimentos que eran atacadas por organismos patógenos y -por otro- sociedades que regulaban su subsistencia y reproducción en la disponibilidad de dichas fuentes. ${ }^{7}$ El presente artículo intenta explicar las circunstancias en que surgieron y evolucionaron dos plagas de langosta en el territorio del actual estado de Oaxaca (1802-1804 y 1853-1857), las secuelas que causaron en las tierras indígenas y las estrategias desplegadas por los autoridades políticas y los pueblos nativos para combatirlas. Cabe señalar que el interés de reflexionar sobre este fenómeno no radica únicamente en sus efectos negativos sobre la cubierta vegetal, sino en vislumbrar las posturas seculares y religiosas para combatir una plaga de artrópodos, ya sea estableciendo cordones preventivos, legislando sobre la materia, fomentando el trabajo comunitario y desplegando una verdadera lucha contra esta calamidad, calificada ya de por sí como "letal" desde mediados del siglo XviII. ${ }^{8}$

de Tehuantepec, siglo xix”, en Desacatos. Revista de Antropología Social, primavera, núm. 1, 1999; Sergio Nicolás Gutiérrez Cruz, "Don Sebastián Esponda y Olaechea, abogado de las Reales Audiencias de México y Guatemala”, en Liminar. Estudios sociales y humanísticos, vol. 5, núm. 2, 2007; "Vínculos sociales y políticos en el partido de Tuxtla, provincia de Chiapas, en el último cuarto del siglo xvıII", en Diálogos. Revista Electrónica de Historia, 2008; Paola Peniche, "Los desastres de 1770 en la península y su impacto en el sistema colonial yucateco", en Gabriela Vera Cortés, coord., Devastación y éxodo. Memoria de seminarios sobre desastres en México, México, Ciesas, Sedesol, Conacyt, 2009, 229246; Tiempos aciagos. Las calamidades y el cambio social del siglo XVIII entre los mayas de Yucatán, México, Ciesas, Miguel Ángel Porrúa, 2010.

${ }^{7}$ Esta propuesta ha sido ampliamente desarrollada por las ciencias biológicas, véase Pierre Duvigneaud, La synthése écologique, París, Doin, 1984; R. L. Metcalf y W. H. Luckmann, Introduction to Insect Pest Management, Nueva York, John Wiley, 1982; A. Steedman, ed., Locust Handbook, Londres, Natural Resources Institute, 1990.

${ }^{8}$ Las plagas de langosta han sido examinadas con mayor detenimiento y enfoques por la historiografía española de los siglos XVII, XVIII, XIX y XX. Esto obedece estrictamente al interés por desarrollar trabajos cuyas premisas se fundan en la historia ambiental y la ecología histórica; asimismo, por la presencia tan recurrente-incluso hoy en 
A pesar de que dichas plagas irrumpieron con igual magnitud en los campos y las montańas de Chiapas, Guerrero, Oaxaca, Tabasco y Yucatán, debo subrayar que mi inclinación por lo ocurrido en Oaxaca radica en tres factores: primero, el acceso a un corpus documental relativamente abundante que registra acuciosamente la perspectiva secular y religiosa que se construyó sobre dichos fenómenos; en segundo lugar, el interés de examinar los estragos de las plagas en poblaciones indígenas cuya subsistencia dependía -en buena medida- de las posibilidades de acceder y labrar terrenos agrícolas; ${ }^{9}$

día- que tienen estos fenómenos en la península ibérica. Al respecto, véase Xavier Sistach, Bandas, enjambres y devastación. Las plagas de langosta a través de la historia, Barcelona, Almuzara, 2007; Milagros León Vegas, "Una simiente devastadora del agro antequerano: la plaga de langosta de 1620”, 285-306, en Revista de Historia Moderna, núm. 23, 2005; Dos siglos de calamidades públicas en Antequera. Crisis epidémicas y desastres naturales (1599-1804), Antequera, Ayuntamiento de Antequera y Fundación Municipal de Cultura, 2007; Armando Alberola Romá, "Procesiones, rogativas, conjuros y exorcismos: el campo valenciano ante la plaga de langosta de 1756", en Revista de Historia Moderna. Anales de la Universidad de Alicante, núm. 21, 2003; Antonio Buj Buj, "Control de plagas de langosta y modernización agrícola en la España de la segunda mitad del siglo xix", en Geo Crítica, Cuadernos críticos de geografía humana, núm. 95, 1992. Para el caso de Hispanoamérica, existen algunos trabajos que abordan indirectamente este tipo de plagas, tal es el caso de Juan Carlos Jurado Jurado, "Terremotos, pestes y calamidades. Del castigo a la misericordia de Dios en la Nueva Granada, siglos XVIII y XIX", en Procesos Históricos, núm. 5, 2004; Bernabé Fernández Hernández, "Problemas de la agricultura de Honduras a principios del siglo xix”, en Temas Americanistas, núm. 7, 1990, 23-27; El gobierno del intendente Anguiano en Honduras (1796-1812), Sevilla, Universidad de Sevilla, 1997, 106-107; Sajid Alfredo Herrera, "Primary Education in Salvador and Sonosante, 1750-1808", en Jordana Dym y Christopher Belaubre, Politics, economy, and society in Bourbon Central America, 1759-1821, Denver, University of Colorado Press, 2006, 1-17; José Germán Pacheco Troconis, El añil: historia de un cultivo olvidado en Venezuela, 1767-1870, Tesis doctoral, Universidad Autónoma de Barcelona, Departamento de Economía e Historia Económica, 2000, 408-409, 453, 473; Oscar Guillermo Pelaez Almengor et al., La ciudad ilustrada: Las influencias del pensamiento ilustrado en el traslado, construcción y organización de la economía de la ciudad de Guatemala, 1776-1821, Informe de Investigación, Universidad de San Carlos de Guatemala, Centro de Estudios Urbanos y Regionales, 2004, 29-35, 4041, 70.

${ }^{9}$ Cabe decir que entre 1800 y 1857, el territorio de Oaxaca se distinguió por tres rasgos: el predominio de la población nativa y -por ende- de los pueblos indios, y el importante papel de las tierras y la economía indígena. Tan sólo durante estos años, la población indígena representó 88 por ciento del total de habitantes, mientras que los pueblos fueron los principales poseedores de las tierras agrícolas y -por ende- los principales actores de la dinámica económica, mercantil y fiscal en Oaxaca. Véase Carlos Sánchez Silva, Indios, comerciantes y burocracia en la Oaxaca poscolonial, 1786-1860, México, 
terrenos que estaban orientados a satisfacer los recursos que demandaban las unidades domésticas y las corporaciones civiles (pueblos) y religiosas (cofradías); en tercer lugar, vislumbrar las estrategias que promovieron las autoridades oaxaqueñas para controlar las plagas y -sobretodo- para transformar la estructura agraria que predominaba en el estado y que desde su perspectiva agravaba las secuelas de estos fenómenos.

\section{"Sembrando El CANUTO DE LA Discordia"}

El ańo de 1800 fue de poca lluvia y altas temperaturas, tanto en el virreinato de Nueva España, como en la Capitanía General de Guatemala. Lo trascendente del hecho fue que se trató del segundo año consecutivo en que las condiciones meteorológicas se presentaban de esta manera. Quizás por eso, las sociedades campesinas del sureste novohispano recibieron las primeras lluvias de mayo de 1801 con misas, procesiones y festividades; incluso, otros tantos sembraron sus terrenos comunes apresuradamente con el objeto de cosechar y almacenar granos para subsistir el siguiente año. En pocas semanas, el horizonte seco se tornó verde con los primeros brotes de maíz, calabaza y frijol. Siguieron meses de lluvias continuas y temperaturas estables, lo que generó cierta seguridad entre los agricultores. Hacia principios de julio, cuando las milpas ya jiloteaban, las lluvias se precipitaron tempestuosamente por dos semanas; no obstante, al iniciar agosto, la porción sur de la Capitanía Mayor de Guatemala fue invadida inesperadamente por miles de enjambres de langosta, al grado de infestar la provincia de San Salvador. Un mes después, la plaga se posicionó en la parte occidental de la capitanía, devastando campos y bosques enteros en las subdelegaciones de Suchitepec y Soconusco. Al tiempo en que esto ocurría, las noticias comenzaron a fluir hacia Nueva Espańa. De inmediato, los primeros síntomas de la plaga se hicieron evidentes. Entre septiembre y octubre, el gobernador de Tabasco refirió que los vientos procedentes de Guatemala

Instituto Oaxaqueńo de las Culturas, Fondo Estatal para la Cultura y las Artes, Universidad Autónoma Benito Juárez de Oaxaca, 1998, 19-22. 
acarrearon "mangas de langostas" que -repentinamente- se precipitaron sobre los pueblos de la costa, causando estragos en los cultivos de maíz y frijol, y despertando pánico entre la población. ${ }^{10}$ En esas mismas fechas, el comandante general de Yucatán señaló que la "plaga de insectos gestada en Guatemala" irrumpió inesperadamente en las subdelegaciones de Sierra Baja y Zotula, provocando daños irreparables en la agricultura y generando conmoción entre los naturales. ${ }^{11} \mathrm{El}$ intendente de Chiapa, entretanto, advirtió que las subdelegaciones de Soconusco, Suchitepec y Zendales estaban infestadas de insectos y solicitó ayuda para exterminarlos, pues de no combatirlos causarían gravísimos perjuicios al erario real, a la gruesa de diezmos y a la población del reino de México "en donde serán mayores los estragos si llega a entrar y multiplicarse la langosta en los fértiles y templados terrenos de Oaxaca". ${ }^{12}$

Así las cosas, en noviembre de 1801, el intendente de OaxacaAntonio Mora y Peysal- informó que los vientos provenientes del sur habían acarreado algunos "nubarrones de langostas" hasta los partidos de Tehuantepec y Teotitlán del Valle; no obstante, subrayaba que -para suerte de aquellas subdelegaciones- los artrópodos fueron recolectados y enterrados; inclusive, con un tono de relativa seguridad, refirió que la sociedad debería darse de palmos ya que el mal fue combatido y exterminado oportunamente. Por el contrario, las respuestas que seguían llegando desde Guatemala referían una plaga que cubría más de trescientas leguas cuadradas, desde Soconusco hasta Nicoya, ocupando tanto las tierras bajas como altas del territorio, y persistiendo por la falta de vientos y la escasa población que la combatía. ${ }^{13}$

Lo interesante es que, tanto en Nueva Espańa, como en Guatemala la langosta fue identificada como una plaga que generaba da-

10 "Sobre una plaga de langosta en la provincia de Tabasco (1801)", Archivo General de la Nación México (en adelante AGNM), Civil, vol. 1746, exp. 7.

11 "Sobre una plaga de langosta en la intendencia de Yucatán (1801-1802)", AGNM, Civil, vol. 1701, exp. 4, ff. 3-6.

12 "Informe del intendente de Chiapas sobre una plaga de langosta (1802)", Archivo General de Indias (en adelante AGI), Estado, 49, núm. 106, ff. 1-2.

${ }^{13}$ Bernabé Fernández Hernández, "Problemas de la agricultura de Honduras a principios del siglo XIX", pp. 23-24. 
ños agrícolas, hambre y desolación. Esta visión no sólo derivó del discurso bíblico que los colonizadores difundieron entre los pueblos, sino también del contacto continuo de las sociedades indígenas con dichos acrídidos que les permitió conocer los alcances y los límites del mismo. Pero ¿Cómo explicar esta visión fatalista que inspiraba el insecto entre la población? Para responder dicha pregunta, conviene revisar la naturaleza del mismo y vislumbrar tanto los alcances como los límites de su condición endémica.

Las langostas referidas fueron insectos cuya clasificación se ubicó en el orden Orthoptera, la familia Acridoidea, el género Lacusta y -desde la perspectiva de Carlos Lineo- la especie migratoria. Es decir, se trató de artrópodos cuya fisonomía se caracterizó por tener cuerpos robustos que iban desde cinco hasta diez pulgadas, cabeza grande y bordeada con antenas, dos pares de alas, patas frontales recortadas y patas posteriores alargadas, y en su mayoría eran fitófagos. También se distinguieron por producir efectos de mimetismo en su coloración, versatilidad en sus alas para volar y capacidad de emitir sonidos por medio de un proceso de estridulación que implicaba el frotamiento de sus cuerpos. ${ }^{14} \mathrm{William}$ Bowles, un viajero irlandés del siglo XviII, señaló que estas características hacían de la langosta el "animal que más se parece a todos los animales [...], porque tiene los cuernos de ciervo, los ojos de vaca, la frente de caballo, las patas de cigüeña, la cola de culebra y las alas de paloma”. ${ }^{15}$

La langosta más nociva fue la perteneciente a los géneros Schistocerca, Nomadacris y Dociostaurus. Sobre los insectos que irrumpieron en Guatemala y el sureste de Nueva Espańa, los relatos de la época permiten distinguir que muy probablemente se trató del género Schistocerca americana y que Linneo definió como altamente peligroso ya que formaba enjambres cuyas dimensiones alcanzaban

\footnotetext{
${ }^{14}$ Anastasio Chinchilla, Memoria sobre los insectos, Madrid, 1844; A. Dampf, Contribuciones a la morfología y biología de Shistocerca, México, Comisión Científica Exploradora de la Plaga de la Langosta en el estado de Veracruz, 1925; G. Malpica, "La langosta", en Revista de las plagas del año, México, 1912; F. Rivas Moreno, La plaga de langosta en México, Argelia y otros países, Madrid, 1888; Ramón Sistach, Bandas, enjambres y devastación, pp. 10-30.

${ }^{15}$ William Bowles, Introducción a la historia natural y a la geografía física de España, Madrid, Imprenta Real, 1782.
} 
hasta los ochocientos metros de longitud. A diferencia de aquellos planteamientos que explican la aparición de estas plagas en relación con las posibilidades edáficas y altitudinales de los terrenos agrícolas, la entomología ha demostrado históricamente que dichos fenómenos irrumpieron en cualquier terreno que -independientemente de sus características- sirvió como hospedante alimenticio a los acrídidos. En este orden, los pastos fueron el alimento predilecto, pero la experiencia demuestra que todo tipo de vegetación -incluso la de parajes desérticos- sirvió como nutriente. ${ }^{16}$

Sobre su condición migratoria, fue una característica que el insecto desarrolló en su etapa adulta; es decir, pasó de una fase solitaria e inofensiva a una gregaria, endémica y migratoria. Según Boris Uvarov, el paso de una etapa a otra no fue repentino, sino que dependió de cada especie y fue resultado de mutaciones biológicas. Dichas mutaciones fueron alentadas por las condiciones ambientales de cada espacio. En muchos lugares, por ejemplo, las plagas surgieron cuando las temporadas de precipitación y crecimiento vegetal fueron antepuestas por sequías y altas temperaturas. En este sentido, la condición gregaria de los insectos fue accionada por su sistema endocrino y se manifestó al tiempo en que se agruparon en busca de vegetación. ${ }^{17}$ La concentración en sí misma significó hambre, mientras que la migración implicó saciar el apetito. Obviamente, la fase endémica se evidenció cuando los "cielos claros se oscurecían y los murmullos de tantos millones de alas formaba un ruido sordo, semejante al que hace un viento seguido en un bosque muy poblado de árboles". ${ }^{18}$

Resulta pertinente notar que el conocimiento científico sobre la fase migratoria sólo fue alcanzado hasta principios del siglo xx. An-

${ }^{16}$ Una amplia argumentación al respecto puede encontrarse en W. Conner Sorensen, Brethren of the Net. American Entomology, 1840-1880, cap. 7, Tuscaloosa, University of Alabama Press, 1995; Ramón Sistach, Bandas, enjambres y devastación, pp. 126-131.

${ }^{17}$ Boris Uvarov, "A Revision of the Generous Locusta with a New Theory...”, pp. 135-163, en The Bulletin of Entomological Research, vol. XII, 1921; Locust and Grisshoppers. A Handbook for their Study and Control, Londres, The Imperial Bureau of Entomology, 1928.

${ }^{18}$ William Bowles, Introducción a la historia natural ..., p. 275. 
tes de esta fecha, la comprensión biológica del artrópodo se redujo a una visión general del insecto inspirada en los sistemas taxonómicos de Linneo, Lamarck y Bufón. ${ }^{19}$ La Corona española, por ejemplo, dispuso de una Ordenanza para proceder a la extinción de la langosta... (1593), un Tratado de las langostas muy útil y necesario... (1620), un Auto acordado por el Consejo Real... (1723) y una Instrucción tomada sobre la experiencia y practicada de varios años para conocer y extinguir la langosta... (1755). ${ }^{20}$ Se sabe que estos documentos circularon en Nueva España y Guatemala desde 1802 por las razones antes expuestas. ${ }^{21}$

Conviene señalar que la Instrucción refirió la biología del insecto y advirtió que su ciclo de vida iniciaba cuando las hembras "desovan y semína la langosta adulta, y antes de morir, hincando y enterrando su aguijón y cuerpo en las dehesas, montes, tierras incultas, duras, ásperas y en las laderas [...] dejando formado un canuto", donde al paso varios meses nacían más de cien larvas. Dichas larvas eran reconocidas como "fetos" o "mosquitos" debido al minúsculo tamaño que tenían al nacer; posteriormente, experimentaban varias mutaciones hasta convertirse en insectos "adultos" o "saltadores". Al tiempo de alcanzar esta fase, se agrupaban en el suelo a manera de una "torta negra" que se desplazaba rápidamente devorando cuanto vegetal encontraba a su paso; luego fortalecían sus alas y adquirían habi-

${ }^{19}$ Elías Trabulse, "La Colonia (1521-1810)”, en Ruy Pérez Tamayo, coord., Historia de la ciencia en México, México, Fondo de Cultura Económica, 2010, 26-27.

20 “Ordenanza para proceder a la extinción de la langosta (1593)", en Antonio Márquez Delgado, La lucha contra la langosta en México, México, Editorial Fournier, 1963, 59-60; "Auto acordado por el Consejo que comprende las providencias para exterminar la langosta (1723)", Archivo Histórico Nacional (en adelante AHN), Consejos, libro 1476, f. 157; Tratado de las langostas muy útil y necesario en que se tratan cosas de provecho y curiosidad para todos los que profesan letras divinas y humanas, y las mayores ciencias, compuesto por el doctor Juan de Quiñones..., Madrid, Luis Sánchez Impresor, 1620; Instrucción tomada sobre la experiencia y practicada de varios años para conocer y extinguir la langosta en sus tres estados de ovación, feto o mosquito, y adulta, con el modo de repartir y prorratear los gastos que se hicieren en este trabajo (1755), Biblioteca Nacional de Madrid (en adelante BNM), Reales cédulas, Signatura/37083.

21 "Bando que manda distribuir la Instrucción tomada sobre la experiencia y practicada de varios ańos para conocer y extinguir la langosta en sus tres estados (1802)", AGNM, Bandos, vol. 22, exp. 63, ff. 177-182. 
lidades para volar, se agrupaban en enjambres y emprendían largas migraciones en busca de alimentos. Durante esta etapa, recibieron el mote de "voladores" y se convirtieron en los bichos más difíciles de combatir debido a su habilidad para desplazarse, engullir la vegetación y "sembrar el canuto de la discordia" en las tierras que pisaban. Al paso de cuarenta o cincuenta días como "voladores" terminaba su ciclo de vida. Para entonces, los dańos causados en el campo y el asombro generado entre los habitantes eran irreparables.

Bien puede decirse que la ofensiva desplegada por los pueblos oaxaqueños contra la plaga en noviembre de 1801 no fue suficiente, como refirió el intendente Mora y Peysal, pues tan pronto el acrídido se posicionó sobre las subdelegaciones de Tehuantepec y Teotitlán del Valle, comenzó a enterrar sus aguijones por toda la intendencia, ya sea "en las dehesas, montes, tierras incultas, duras, ásperas y laderas, dejando formado canutos [...] con huevecillos". Durante los meses siguientes, el insecto creció y avanzó progresivamente por el territorio oaxaqueño. Si bien esto evidenció la evolución natural de la plaga, también puso de relieve las pocas acciones coordinadas para combatirla. Basta decir que las primeras instrucciones que giró el virrey Félix Berenguer de Marquina (1801-1803) al respecto, se fundaron en el bando publicado por el virrey Gálvez el 11 de octubre de 1785 a efecto de que prevenir el desabasto de alimento y evitar que unos pueblos no carecieran de los granos que les sobraban a otros. 22

Así, las primeras noticias que revelaron la condición gregaria del insecto se conocieron entre julio y diciembre de 1802 y llegaron procedentes de las subdelegaciones de Tehuantepec, Teotitlán del Valle y Villa Alta. En esta última, los comunicados advertían que enjambres de langosta volaban a mediana altura hacia las tierras fértiles de Santa María Lachixila, San Juan Teotalcingo, Santa María Yahuive, Santiago Choapam y San Juan Comaltepec. Al respecto, el subdelegado -José Carlos de Gordón y Urquijo- recomendó que, para evitar la "destrucción de sementeras [...] y las fatales consecuen-

${ }^{22}$ Véase "Sobre una plaga de langosta en la provincia de Tabasco (1801)", AGNM, Civil, vol. 1746, exp. 7, ff. 5-55. 
cias que de su efecto resultan", los naturales persiguieran y exterminaran los enjambres que encontraran a su paso. ${ }^{23}$ Un mes después, en enero de 1803, las "noticias sobre la venida de la langosta" provinieron desde las subdelegaciones de Cuatro Villas y Zimatlán, y revelaban que aunque no era excesivo el número de enjambres sí estaban causando daños en el campo, ya que luego de destruir las sementeras se alimentaban de la corteza y las hojas de árboles. ${ }^{24}$ Conforme pasaron los meses, los informes relacionados con la plaga se tornaron alarmantes: por una parte, advertían la expansión geográfica de los insectos en el sur, sureste, centro y noreste de la intendencia; por otra parte, anunciaban daños irreparables en las tierras de cultivo. En mayo de 1803, por ejemplo, el subdelegado de Jicayán mencionó que la plaga se apoderó de los pueblos de Tututepec y Juquila, y avanzó progresivamente por la costa en dirección al partido de Ometepec en la intendencia de Puebla; en junio, el subdelegado de Tehuantepec refirió un inmenso enjambre de insectos en el pueblo de Juchitán y proporcionó referencias de artrópodos en los pueblos que colindaban con la subdelegación de Nejapa; en esas mismas fechas, el subdelegado de Teotitlán del Valle reportó que los insectos habían devorado las sementeras de San Pedro Quiatoni causando un desastre irreparable en la agricultura; entretanto, el subdelegado de Teococuilco -en la Sierra Zapoteca- no dudó en exponer que su partido estaba infestado de acrídidos y requería de instrucciones para contener su avance ${ }^{25}$ (véase mapa 1).

Como puede observarse, la plaga de artrópodos avanzó sobre la intendencia de Oaxaca en tan sólo ocho meses. Lo anterior se expli-

23 "Sobre la presencia de langosta en varios pueblos de Villa Alta (1802)", Archivo del Juzgado de Villa Alta (en adelante AJvA), Civil, leg. 35, exp. 14, f. 1. A juzgar por el conocimiento entomológico, se reconocen dos tipos de enjambres: los estratiformes y los cumuliformes. En los primeros, las nubes de insectos vuelan a baja altitud y la anchura de su capa no rebasa los 20 metros; en los segundos están asociados a corrientes de conversión térmica, vuelan a gran altitud y formas capas que llegan a medir más de tres kilómetros de largo.

24 "Noticias de las providencias dictadas por este virreinato para el exterminio de la plaga de langosta que apareció en algunas poblaciones de la provincia de Oaxaca”, en Antonio Márquez Delgado, La lucha contra la langosta en México, pp. 77-78

25 "Sobre exterminar la plaga de langosta aparecida en la intendencia de Oaxaca (1803)”, AGNM, Civil, vol. 1701, exp. 1, f. 108. 


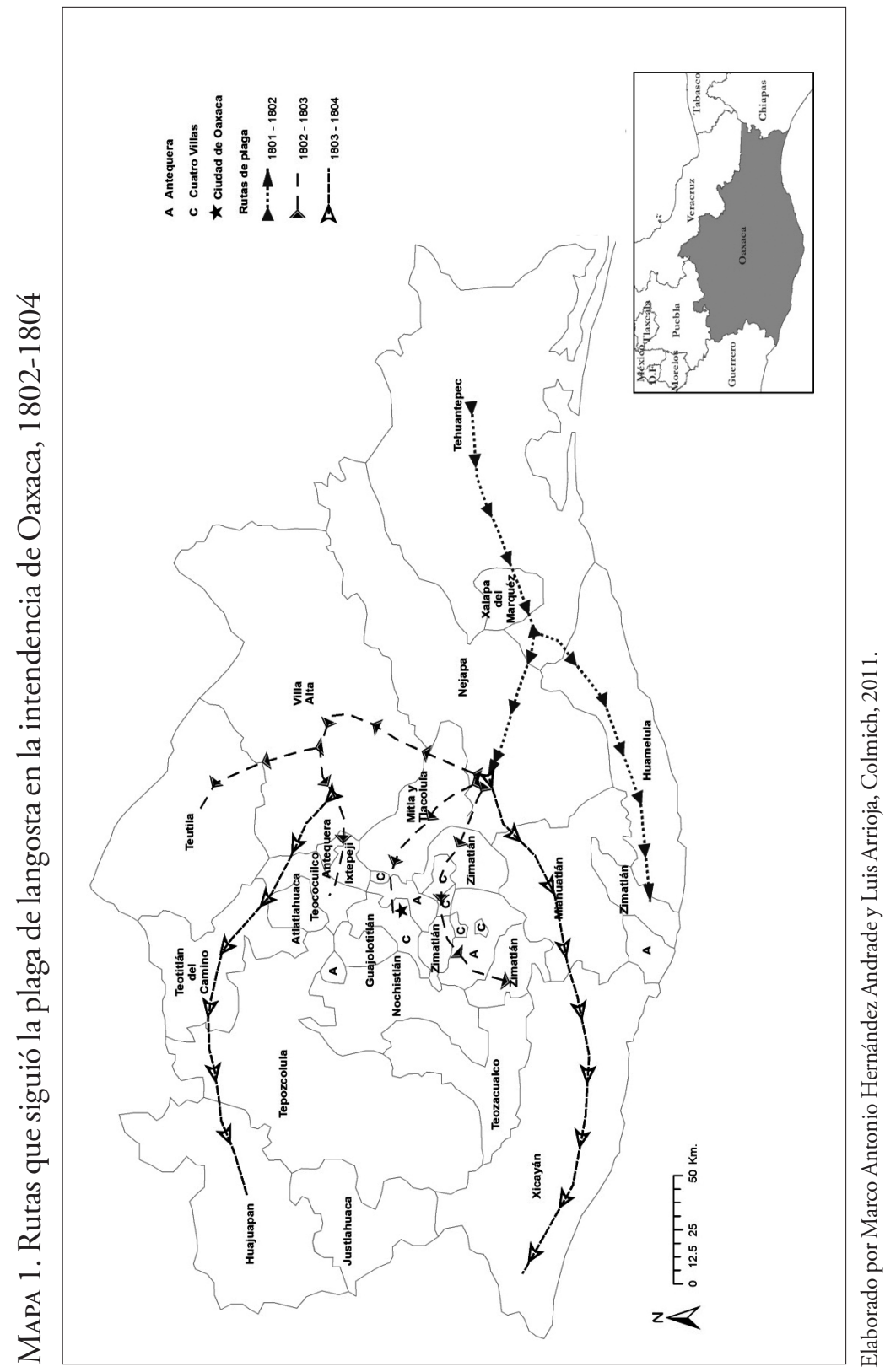


ca en el entendido de que los canutos depositados en la tierra entre 1801 y 1802 se convirtieron en "langostillos" y permanecieron en las inmediaciones devorando cuanto vegetal estuvo a su alcance hasta alcanzar su etapa adulta en la que, además de renovar su ciclo biológico, se agruparon en enjambres y conformaron "una nube que interceptó los rayos del sol e inició sus terribles vuelos sobre los campos" ${ }^{26}$ Tal vez lo más grave del asunto radicó en que la plaga no sólo se extendió hasta las vecinas intendencias de Puebla y Veracruz, sino que permaneció en el territorio oaxaqueño hasta 1804. En junio de aquel ańo, por ejemplo, el subdelegado de Tehuantepec mencionó que, pese a las acciones libradas contra la langosta, ésta había devastado muchas sementeras e incluso causado la indigencia en aquellos pueblos que carecían de reservas. ${ }^{27}$ En septiembre del mismo año, el subdelegado de Teotitlán del Valle reveló con gran preocupación que los insectos habían producido daños graves en treinta pueblos de la jurisdicción, pues "ya saltan estos a los sembrados y los devoran, como si les lloviese fuego [...], ya oigo decir que está metida la langosta hasta en los hogares [...], los campos están colmados y los daños que causan son tan rápidos que [...] son capaces de conducir a los pueblos a los más funestos extremos". ${ }^{28}$ Por si esto no fuera suficiente, el intendente Mora y Peysal reportó que la guerra contra la langosta podría perderse en caso de no desplegar acciones contundentes, pues de lo contrario los recursos agrícolas de la intendencia estaban condenados a sucumbir. ${ }^{29}$ Ante las dimensiones de la plaga, conviene preguntarse ¿Cuáles fueron las acciones emprendidas por las autoridades oaxaqueńas?

${ }^{26}$ William Bowles, Introducción a la historia natural ..., pp. 269-270.

27 "Sobre la presencia de langosta en varios pueblos de Tehuantepec (1804)", Archivo General del Estado de Oaxaca (en adelante AGEO), Real intendencia, Subdelegaciones, Tehuantepec, exp. 14, f. 1 .

28 "Sobre la presencia de langosta en los pueblos de Teotitlán del Valle (1804)", AGEO, Real intendencia, Subdelegaciones, Teotitlán del Valle, exp. 41, ff. 1-3. Los estudios entomológicos recientes advierte que los enjambres de langosta son capaces de volar entre diez y doce horas diarias, al grado de completar entre 200 y 400 kilómetros en una jornada completa.

29 "Informe del intendente de Oaxaca sobre las acciones para combatir la plaga de langosta (1804)”, AGNM, Civil, vol. 1701, exp. 3, f. 100. 


\section{BANDOS, INSTRUCCIONES Y REGLAMENTOS PARA EXTERMINAR LA LANGOSTA}

Las medidas de las autoridades virreinales para contener la plaga de langosta fueron complejas y desiguales. El virrey Berenguer de Marquina, por ejemplo, abordó el problema con acciones muy tenues, pues las pocas que desplegó estaban encaminadas a remediar, primero, su reputación como funcionario real y, segundo, el impacto de los insectos en las tierras agrícolas. Como ya he referido, una de sus providencias se ancló en el bando de 11 de octubre de 1785, situación que no sólo reveló el desconocimiento del jerarca sobre la naturaleza del problema, sino también que confundía el fenómeno mismo con los resultados que acarreaba. En efecto, el bando no incluyó noticias sobre la plaga de langosta; por el contrario, estipuló que el problema era la escasez de granos debido a las cosechas pobres y la especulación de precios; ante esto, recomendaba promover siembras en tierras calientes y húmedas, y castigar la especulación. Muy probablemente, esta orden palió de alguna manera la escasez de granos; sin embargo, no contuvo el ciclo reproductivo y la proliferación de insectos.

La segunda medida desplegada por Berenguer de Marquina quedó plasmada en el bando de 16 de agosto de 1802;30 un instrumento que planteaba íntegramente la Instrucción tomada sobre la experiencia y practicada de varios años para conocer y extinguir la langosta... de 1755 y -por ende - trazaba a lo largo de un prolijo articulado las recomendaciones que debían seguir las autoridades y los vecinos de pueblos infestados por langostas. Revisando detenidamente dicha Instrucción, salta a la vista que fue redactada entre 1754 y 1755 por el Consejo de Castilla y se compuso de treinta y uno artículos, una comunicación, un auto acordado y una adición. Respecto a los artículos, se agruparon en cuatro categorías: primera, el estado de ovación o canuto del insecto (Arts. 1-8); segunda, el estado de feto o mosquito (Arts. 9-11); tercera, el estado de adulta o saltadora (Arts. 12-19); cuarta, los gastos y modo de repartirlos (Arts. 20-31).

30 "Bando sobre el modo de combatir la plaga de langosta (1802)", AGNM, Bandos, vol. 22, exp. 63. 
Cuando en la Instrucción se emplean las palabras conocer y extinguir, éstas no refieren el simple acercamiento y erradicación del insecto, sino que implican un racionalismo donde predominan las acciones humanas -meditadas y lógicas- encaminadas a extinguir la calamidad. Así, en la primera categoría de artículos, se insta a las autoridades, "pastores, labradores y guarda montes" a recabar información sobre los sitios donde pululaban insectos, ya sea en estado solitario o gregario; también exhorta a destruir aquellos que se encontraban como canutos en la tierra, especialmente durante el otońo o invierno ya que eran temporadas en que las superficies húmedas resultaban más fáciles de remover. Enseguida, recomienda deponer la tierra y colectar los canutos, ya sea arando con rejas, rastrillos, azadones, barras de hierro o "ganados de cerda que osando y revolviendo la tierra se comen el canuto, por ser aficionados a él, y les engorda mucho por lo jugoso y mantecoso que es". ${ }^{31}$ En la segunda categoría de artículos, se advierte que cuando los insectos alcancen el estado de "feto o mosquito" se empleará todo género de ganado con el objeto de pisotearlos y engullirlos; igualmente, insta a emplear el fuego para erradicar las plagas de ciertos terrenos y, sobre todo, reunir a los vecinos de cada pueblo para exterminar los artrópodos, ya sea pisándolos o golpeándolos con suelas de cuero, cáńamos, espartos, correas y palos; inclusive, recomienda quemarlos y enterrarlos en fosas de tres o cuatro varas de profundidad.

La tercera categoría de artículos se concentra en la "etapa adulta" de los insectos y manda continuar los procedimientos anteriores, aunque recomienda realizarlos preferentemente de noche ya que es el momento en que la langosta suele "estar entorpecida, parada y acobardada"; de la misma manera, exhorta a los vecinos a disponer de una herramienta llamada "bueytron", confeccionada con costales y largos bastones de madera que permitan atrapar los insectos que se alojaban en copas de árboles y lechos de arbustos. Obviamente, todas estas acciones implicaron altos costos humanos y materiales. Ante esto, la cuarta parte del articulado dispuso que los recursos para combatir dicha plaga se obtuvieran de los propios y arbitrios de

${ }^{31}$ Instrucción tomada sobre la experiencia y practicada..., Art. 6. 
cada pueblo y ordenó que -en caso de no disponer de propios y arbitrios- las autoridades de cada pueblo organizaran un repartimiento "entre los interesados en diezmos, hacendados y demás vecinos [...] para que siendo uno el fin, y común la utilidad, contribuyan al remedio y la aflicción en que se arriesgan todos". ${ }^{32}$ En caso de no existir recursos para combatir la plaga, existió la posibilidad de que la Corona autorizara socorros oportunos y fijara las reglas más conducentes para combatir este mal.

Es importante señalar que el auto acordado y la adición reiteraron lo expuesto en el articulado y pusieron al descubierto una explicación que -en la mejor tradición fisiocrática- manifestaba que la langosta era un "animal lascivo" que encontraba sus condiciones de reproducción en los campos baldíos, las dehesas y las tierras incultas de los pueblos. Frente a dicha perspectiva y bajo recomendaciones del Conde de Campomanes, se ordenó que los pueblos repartieran entre sus vecinos las tierras incultas de dominio concejil y roturaran a la brevedad los baldíos con semillas ávidas en los mercados locales y regionales.

Lo interesante de resaltar es que el predicamento de la Instrucción fue detenido por el mismo virrey Berenguer de Marquina un mes después de su publicación -en septiembre de 1802- por considerar que la plaga se había extinguido en las jurisdicciones afectadas. ${ }^{33}$ No obstante, el problema continuó e incluso se agudizó hasta el grado que el virrey José de Iturrigaray Aréstegui (1803-1808) mandó redactar, de conformidad con los fiscales del Real Acuerdo, una Noticia sobre las Providencias Dictadas para el Exterminio en este Virreinato de la Plaga de Langosta... ${ }^{34}$ en la cual instó al intendente de Oaxaca emplear la Instrucción de 1755 para evitar la propagación del insecto; también le exigió arreglar el tema de las semillas y librar -en caso de progresar rápidamente dicha plaga- órdenes sobre las tesorerías y administraciones de rentas con el objeto de comprar granos y abas-

32 Instrucción tomada sobre la experiencia y practicada..., Arts. 28, 30.

33 "Instrucción tomada sobre la experiencia y practicada... (1802)", AGNM, Bandos, vol. 22, exp. 63, ff. 177-182.

${ }^{34}$ Noticia sobre las Providencias Dictadas para el Exterminio en este Virreinato de la Plaga de Langosta... (1803), AGNM, Bandos, vol. 23, exp. 40, ff. 97-98. 
tecer las alhóndigas y pueblos; inclusive, mandó investigar "por medios secretos y disimulados" las reservas de granos en la intendencia y en las colectarías del obispado de Antequera. Obviamente, la gravedad de la plaga provocó que las autoridades virreinales no dudaran en desplegar medidas más contundentes: se habló de recompensar a los vecinos que colectaran y mataran los insectos, destinar una bolsa especial para abatir los artrópodos en los partidos de Cuatro Villas, Zimatlán, Ocotlán y Ayoquesco, y promover rogativas en todas las parroquias para implorar el fin de dicha calamidad.

Hasta donde puede observarse, las acciones desplegadas no fueron las más eficaces ya que el insecto continuó reproduciendo su ciclo biológico y desplegando su condición gregaria. Cabe decir que la dificultad para romper este ciclo se explica -en cierta medidapor la geografía oaxaqueña que impidió roturar oportunamente las múltiples quebradas y laderas donde se gestaban las larvas. A esto habría que ańadir las oscilantes condiciones ambientales que se presentaron entre 1802 y 1804 -lluvias esporádicas acompañadas de altas temperaturas-, la incapacidad de los indígenas para lidiar con miles de bichos que consumían sus campos, la falta de recursos para recompensar el trabajo de aquellos que colectaban y enterraban los insectos, y la carencia de condiciones humanas y materiales para instrumentar al pie de la letra las instrucciones reales.

La situación fue tan grave que el intendente de Oaxaca no dudó en dirigirse a todos los subdelegados y señalarles que "no habiendo producido las providencias dictadas hasta ahora sobre la extinción de langosta todo el efecto que me había propuesto", mandaba seguir al pie de la letra un documento de su autoría que llevaba por título "Reglas dictadas por el intendente de Oaxaca para el exterminio de la langosta". ${ }^{35}$

35 "Reglas dictadas por el intendente de Oaxaca para el exterminio de la langosta (1804)”, AGNM, Civil, 1701, exp. 3., ff. 35-39. Una copia del mismo documento puede encontrarse en otro acervo con la siguiente referencia "Instrucciones del intendente de Oaxaca para combatir la langosta (1804)", AJva, Civil, leg. 35, exp. 22., ff. 1-3. En el caso de la capitanía de Guatemala se publicó en estas mismas fechas un documento con las mismas características, véase Instrucción sobre la plaga de langostas, medios de exterminarla o de disminuir sus efectos y de precaver la escasez de comestibles. Dispuesta de orden del superior gobierno de Guatemala, por el licenciado don José de Valle, abogado de esta Real Audiencia, Guatemala, Impresa por don Ignacio Beteta, 1804. 
Observándolas con atención, puede decirse que estas pautas siguieron la misma tendencia de los documentos antes expuestos: referir estrategias para evitar su propagación al más puro estilo escolástico -especulando y ajenos a la comprobación empírica- y enunciar los estragos que acarreaba en los campos de cultivo. Así, los primeros dos incisos advertían a la población "no espantar por ningún título la langosta", ya que esto despertaba sus instintos y propiciaba que buscara alimento; también sugerían aprovechar el fresco de la noche y del amanecer - "momentos que entorpecen a dicho insecto"- para recogerlos, matarlos e introducirlos en zanjas. Los incisos 3, 4, 5 y 6 invitaban al subdelegado a formar cuadrillas de indios para realizar tareas de recolección y exhumación, e informar sobre la irrupción y el exterminio de bichos. El inciso 7 exhortaba a la población a abstenerse de prender fuego en los campos donde pernoctaban los artrópodos "por el peligro que corren los zacatales de los pueblos y las chozas de los indios que cuidan de las milpas" Los incisos 8 y 9 sugerían emplear todos los medios para obligar a los naturales a combatir la langosta en todos sus estados de vida, so pena de castigarlos en caso de negarse. El inciso 10, por su parte, instruía a los subdelegados a evitar que los naturales consumieran estos artrópodos ya que -a diferencia de las especies comestibles- podían causarles enfermedades gastrointestinales. El inciso 11 persuadía a la población para realizar siembras en fechas oportunas, almacenar granos e impedir la especulación de precios. Finalmente, el inciso 12 invitaba a los párrocos a implorar el socorro del cielo con el objeto de exterminar la plaga.

Las "Reglas dictadas por el intendente" llegaron a la cámara del virreinato donde fueron aprobadas e incluso consideradas para repartirse en aquellas intendencias que padecían la plaga. Pese a las recomendaciones desplegadas, lo cierto es que dichas acciones no fueron contundentes para vencer al insecto e incluso acarrearon algunas secuelas económicas para los pueblos, ya sea obligarlos a rentar yuntas y herramientas para remover sus tierras; dilapidar cajas comunes para sufragar las acciones contra la plaga; y penalizar a los naturales que no cumplían con los requerimientos de los subdelegados. En vista de los pocos avances generados por las instrucciones, 
conviene preguntarse ¿cómo actuaron los pueblos para contener este infortunio natural?

\section{Posturas y ACCIONES EN LOS PUEBLOS}

Sin lugar a dudas, la plaga de langosta de 1802-1804 se extendió geográficamente por numerosos pueblos de la intendencia de Oaxaca, aunque sus estragos se sintieron mayormente en las subdelegaciones de Cuatro Villas, Jicayán, Miahuatlán, Nejapa, Tehuantepec, Teococuilco, Teotitlán del Camino, Teutila y Villa Alta. En el marco de esta calamidad, muchos naturales observaron cómo los insectos devoraron rápidamente sus milpas y árboles frutales. Para quienes criaban grana cochinilla y cultivaban vainilla, algodón, pita y añil, la pérdida de su producción significó un deterioro económico irremediable. Sin embargo, conviene subrayar que existió una gran diferencia entre ver destruidas las tierras destinadas para la producción comercial y ver desahuciadas las parcelas dedicadas para la producción de subsistencia. Dado esto, no es casualidad que los mayores estragos se sintieran entre los indios comunes que subsistían usufructuando pequeñas parcelas de común repartimiento.

Desafortunadamente, las víctimas hablan poco sobre su desventura; no obstante, la gravedad de la plaga fue capaz de despertar la atención y la opinión de las autoridades. En varios documentos oficiales pueden leerse referencias sobre los estragos y las reacciones en los pueblos indios. En buena parte de ellos se reitera el destrozo de siembras y la escasez de alimentos. La autoridad de Cuatro Villas, al señalar la presencia de insectos en Santiago Ocotlán, advertía que

transitó por aquella cabecera una manga horrorosa de langosta que comenzó desde las dos y media del día de ayer y no cesó sino hasta las cinco en que un aguacero la cortó; por lo que la gradúo en tres leguas de largo y otras tantas de ancho, bien que detrás de esta venía otra muy considerable que traía la misma dirección, y que habiéndose reconocido esta mañana el daño no se habían visto devorados más que milpas [...] quedando aquellos naturales ocupados en matarla y ahuyentarla. 
El subdelegado de Jicayán, por su parte, refirió en julio del mismo ańo que "la langosta había hecho mansión en los bajos de Tututepec, causando en las sementeras el mayor destrozo sin poderlo remediar, la demás que ha aparecido se dirige [...] por toda la costa tomando el rumbo de Acapulco". ${ }^{36}$

Cierto es que algunos naturales solían subsistir, en años malos, racionando sus reservas de granos hasta que llegaran las cosechas de temporal; otros preferían consumir animales de corral, árboles frutales, raíces que crecían en sus solares o plantas comestibles que proliferaban en los montes. Sin embargo, estas estrategias también se redujeron al tiempo en que irrumpió la plaga; es decir, escasearon los recursos y-consecuentemente- aumentaron los precios de los granos. Frente a dicha situación, no quedó más que implorar el socorro del cielo y apiadarse a santos benévolos. El primero en practicar estas acciones fue el obispo de Antequera, pues en agosto de 1802 encabezó una procesión y solicitó a los párrocos de su diócesis exponer permanentemente el santísimo e interpelar rezos para subsanar la gravedad de la plaga, pues desde su perspectiva este fenómeno simbolizaba un infortunio. El subdelegado de Villa Alta hizo lo propio en julio del mismo ańo, solicitando a los curas de varios pueblos hacer ayunos, rogaciones y demás demostraciones piadosas para "alcanzar por este medio y más acertado, del altísimo y misericordioso Dios, la destrucción de enemigos tan nocivos como plaga”. ${ }^{37}$ En Jicayán sucedió algo semejante, pues el subdelegado refirió que "los sacerdotes no han cesado de conjurar la plaga, hacer misas de rogación ni menos de elevar a Dios los votos de un pueblo tan afligido de un azote que hace tanta sensación" ${ }^{38}$ En este contexto de fervor, algunas autoridades ordenaron restringir las festivida-

36 "Extractos de noticias recibidas sobre la langosta y las prevenciones hechas con este motivo (1803)”, AGNM, Civil, vol. 1701, exp. 1, ff. 104, 115.

${ }^{37}$ Inclusive, esta postura del subdelegado está respaldada en la cordillera del obispo. Lo anterior puede constatarse en "Comunicado del subdelegado de Villa Alta a los pueblos de la jurisdicción sobre la presencia de langosta (1802)”, AJva, Civil, leg. 35, exp. 14, ff. $1-1 \mathrm{v}$.

38 "Extractos de noticias recibidas sobre la langosta y las prevenciones hechas con este motivo (1803)", AGNM, Civil, vol. 1701, exp. 1, f. 123. 
des religiosas e instruyeron a los párrocos para sacar en procesión cuantas vírgenes y santos tenían en los templos.

Cabe señalar que muchos pueblos no se contentaron con suplicar al cielo para que los librara de la plaga y, mejor aún, pusieron en práctica el viejo adagio "a Dios rogando y con el mazo dando". Sin embargo, las acciones combativas se enfrentaron con un obstáculo: la escasez de recursos económicos y humanos. Sea de ello lo que fuera, los primeros esfuerzos de las autoridades nativas se concentraron en sensibilizar a la población para formar cuadrillas que roturaran las tierras con el objeto de romper los canutos o, al menos, sacarlos a la superficie para pisarlos, amontonarlos o quemarlos en grandes hogueras. Hasta donde puede observarse, el personal que se ocupó de estas tareas se integró por funcionarios de república, indios comunes e incluso autoridades coloniales. En la villa de Tehuantepec, por ejemplo, el subdelegado conformó una junta para combatir la langosta que agrupó - entre otros-al párroco de la villa, al coronel comandante de milicias, al administrador de rentas y a los gobernadores de las repúblicas de indios; personajes que -a su vezcoordinaron la formación de "cuadrillas exterminadoras" en los pueblos, informaron sobre los mandamientos y las órdenes reales, recaudaron y distribuyeron los efectos conducentes, convocaron a juntas de trabajo, acordaron providencias y reportaron semanalmente los avances obtenidos. ${ }^{39}$ En los pueblos de Jicayán, las cuadrillas se integraron con indios comunes que perseguían los artrópodos a lo largo de montes y cañadas, y se auxiliaban con instrumentos de labranza para erradicarlos. ${ }^{40}$ En Teotitlán del Valle, los encargados de combatir este infortunio fueron los funcionarios de las repúblicas de indios que "trabajan con tesón en aniquilar la plaga, estrechados por las providencias y las puniciones del subdelegado"; asimismo, una veintena de tenientes que iban "con entereza y actividad [...] haciendo que los pueblos y haciendas salgan a matar langosta que tengan en sus términos, y que cuando haya aniquiladose en unos, pase a

39 "Acuerdos que se tomaron en la junta provincial sobre el combate a la langosta (1804)”, Ageo, Real intendencia, Subdelegaciones, Tehuantepec, exp. 1. ff. 1-2.

40 "Extractos de noticias recibidas sobre la langosta y las prevenciones hechas con este motivo (1803)", AGNM, Civil, vol. 1701, exp. 1, f. 189. 
auxiliar a aquellos en que aún subsiste". ${ }^{41}$ Si bien es cierto que el trabajo de las cuadrillas coadyuvó para contener el avance de la plaga, también es verdad que en muchos lugares el combate fue infructuoso debido a la infinidad de "canutos e insectos que se escondían en las malezas y parajes más incultos [...] y que ahora han fecundado y esparcido de nuevo esta terrible plaga". ${ }^{42}$

Debe aclararse que así como existió solidaridad y organización en muchos pueblos, en otros tantos persistió la indiferencia y la confusión respecto a la plaga. Una prueba de ello ocurrió en la subdelegación de Zimatlán en 1803, fecha en que las autoridades desatendieron los extrańamientos del intendente y omitieron reportar el curso que seguía la plaga. Se sabe que el subdelegado prefirió concentrar su atención en los repartimientos de mercancías y dejar en segundo plano las acciones contra la langosta. Lo anterior provocó que el intendente arremetiera en su contra y le ordenara tomar cartas en el asunto. Ante esto, el subdelegado respondió disculpándose por "no haber tenido noticia de la entrada de la langosta en los pueblos del distrito, pero que en vista de las instrucciones recibidas había expedido las convenientes para que estos pueblos se hallen prevenidos de la langosta”. Desde la postura del intendente, esta respuesta fue tardía ya que el insecto invadió la jurisdicción y provocó daños graves en la agricultura, al grado de escasear los granos entre la población. ${ }^{43}$

Otro caso de desgano ocurrió en San Miguel Tilquiapán en 1803. En aquella ocasión, los naturales de Santa Catarina Minas se dirigieron al intendente de Oaxaca para hacer de su conocimiento que los vecinos de Tilquiapán -jurisdicción de Zimatlán- se negaban a combatir la plaga aduciendo que carecían de recursos para sumarse a las cuadrillas de trabajo. También expresaron que, en caso de persistir la negativa entre los vecinos de dicho pueblo, se corría el

41 "Sobre la presencia de langosta en los pueblos de Teotitlán del Valle (1804)", AGEO, Real intendencia, Subdelegaciones, Teotitlán del Valle, exp. 41, ff. 1-3.

42 "Extractos de noticias recibidas sobre la langosta y las prevenciones hechas con este motivo (1803)", AGNM, Civil, vol. 1701, exp. 1, f. 98.

43 "Extractos de noticias recibidas sobre la langosta y las prevenciones hechas con este motivo (1803)", AGNM, Civil, vol. 1701, exp. 1, ff. 105-106, 110-111. 
riesgo de que otros pueblos "imitaran su ejemplo y se daría el caso de que no hubiese gente con quién perseguir dicho insecto". Ante este problema, el intendente sancionó económicamente a los vecinos de Tilquiapán y reprendió a sus autoridades con varios días de cárcel bajo el argumento de que la plaga era una amenaza para la población y el negarse a combatirla una forma de perjudicar a los naturales. ${ }^{44}$

Como puede observarse, las cuadrillas de trabajo resultaron efectivas para destruir la langosta en su fase de pulgón pero no en su fase migratoria. Obviamente, cuando el acrídido alcanzó su condición gregaria fue necesario desplegar otros recursos para combatirlo. Lo interesante del caso es que dichos recursos no guardaron correspondencia con las instrucciones que divulgaron las autoridades coloniales. Por el contrario, los métodos más socorridos derivaron del conocimiento indígena y consistieron en incinerar los campos donde pernoctaban y anidaban los insectos, generar cortinas de humo para reorientar su vuelo y espantar los nubarrones con ruidos ensordecedores. No obstante, estas acciones acarrearon algunas implicaciones. Una de ellas, por ejemplo, fue el riesgo de que la quema de campos se extendiera a los predios, solares o bosques inmediatos; la otra consistió en alterar las condiciones de fertilidad en las tierras afectadas, pues el hecho de incinerar la vegetación trajo consigo una degradación de nutrientes en los suelos.

Revisando las técnicas utilizadas por los pueblos, puede decirse que la más socorrida fue construir hogueras con palos y ramas secas, encenderlas y generar cortinas de humo al tiempo en que volaban los "nubarrones de langosta"; cortinas que -en la práctica-solamente reorientaron el vuelo de los insectos pero no contuvieron su instinto devorador. Un testimonio del subdelegado de Teotitlán del Valle es muy ilustrativo al referir que "atendiendo a que los humos no hicieron retirar la langosta pues, aunque esta se levanta, vuelve a dejarse caer y ha consumido mucha parte de las sementeras". ${ }^{45}$ Algo semejante señalaron los justicias de Santiago Ocotlán al decir que,

44 "Extractos de noticias recibidas sobre la langosta y las prevenciones hechas con este motivo (1803)", AGNM, Civil, vol. 1701, exp. 1, f. 111.

45 "Extractos de noticias recibidas sobre la langosta y las prevenciones hechas con este motivo (1803)", AGNM, Civil, vol. 1701, exp. 1, f. 99. 
luego de enterarse de que una nube de langosta pasó por la Hacienda de la Soritana, instruyeron a los indios comunes quemar suficientes ramas para que los insectos "levantasen y tomasen hacia las sierras del pueblo de San Sebastián de las Justos, cuyos naturales excitados [...] la arrojaron de igual manera para el cerro grande de Santa Rosa, en el distrito de Zimatlán”. ${ }^{46}$

En estrecha relación con esto, los pueblos de Santa María Ejutla, San Miguel Ejutla y San Agustín Amatenango elaboraron "antorchas de zacate" con el objeto de remover los insectos y obligarlos a posicionarse en "parajes donde pudiesen matarse más fácilmente". ${ }^{47}$ En el pueblo de San Pedro Jicayán, por su parte, construyeron globos de papel que fueron lanzados e incendiados al tiempo en que volaban las nubes de langosta por las sementeras. ${ }^{48}$

Otro recurso para disipar insectos fue el ruido. Éste se produjo con explosiones de cohetes, disparos de armas de fuego, detonaciones de "bombas de pólvora", entonaciones de instrumentos musicales y repiques de campanas. Al igual que las cortinas de humo, el ruido solamente ahuyentó por algunos momentos el paso de insectos. Al respecto, las autoridades de San Pedro Jicayán advirtieron que el arbitrio más eficaz para combatir esta plaga era "quemar mucha pólvora, hacer susurro con los tiros de fúsiles, escopetas, trabucos, y fomentar grandes hogueras", esperando que levantaran el vuelo y dejaran de comerse las sementeras. ${ }^{49}$ Las autoridades de la subdelegación de Huajuapan, por su parte, subrayaron que el estruendo de cohetes y el ruido de la "gente bullanguera" sólo ahuyentaban temporalmente los insectos, pues al poco tiempo se posicionaban en árboles y arbustos. ${ }^{50}$

46 "Extractos de noticias recibidas sobre la langosta y las prevenciones hechas con este motivo (1803)", AGNM, Civil, vol. 1701, exp. 1, f. 106.

47 "Extractos de noticias recibidas sobre la langosta y las prevenciones hechas con este motivo (1803)", AGNM, Civil, vol. 1701, exp. 1, f. 110.

48 "Extractos de noticias recibidas sobre la langosta y las prevenciones hechas con este motivo (1803)", AGNM, Civil, vol. 1701, exp. 1, f. 185.

49 "Extractos de noticias recibidas sobre la langosta y las prevenciones hechas con este motivo (1803)”, AGNM, Civil, vol. 1701, exp. 1, f. 185.

50 "Extractos de noticias recibidas sobre la langosta y las prevenciones hechas con este motivo (1803)”, AGNM, Civil, vol. 1701, exp. 1, f. 198. 
Ciertamente, este tipo de noticias continuaron vigentes en buena parte del sureste novohispano hasta septiembre-octubre de 1804; posteriormente, ganaron terreno aquellas que referían la ausencia de lluvia y la baja de temperaturas. Tengo la impresión de que este cambio climático alteró el ciclo de vida en los artrópodos, pues desde la perspectiva de los entomólogos- cuando la cubierta vegetal era abundante, las temperaturas diurnas templadas y las lluvias esporádicas, los insectos encontraban las mejores condiciones para nacer, crecer y multiplicarse; no obstante, cuando las temperaturas bajaban y las lluvias aumentaban en exceso los insectos morían sin alcanzar su condición gregaria. ${ }^{51}$

Así las cosas, puede decirse que fueron los hechos climáticos que se presentaron en la Nueva España, en general, y Oaxaca, en particular-entre 1804 y 1805- los que contuvieron el avance de la plaga y acarrearon cierto sosiego para los pueblos. Lo anterior fue documentado indirectamente por el subdelegado de Teutila en $1806 \mathrm{al}$ referir que: "librados de la langosta [...] ahora hemos perdido las milpas casi seguidamente, ocasionando este daño el frío [...] y por eso me he visto en la estrecha y penosa necesidad de recurrir a su socorro desde fines del año de 1805 hasta el presente". ${ }^{52}$

Sea de ello lo que fuera, lo cierto es que después de 1805 los pueblos oaxaqueńos experimentaron un periodo de remisión, durante el cual no irrumpieron plagas de langosta a gran escala. Desafortunadamente, las cosas cambiaron cuarenta y ocho años después. En junio de 1853, el gobernador del estado de Oaxaca recibió un comunicado donde le informaban sobre la presencia de una "mancha de langosta” en el pueblo de Tonalá, Chiapas, la cual se movía con rapidez causando estragos en las milpas. Al paso de unas semanas, los informes referían que la mancha se encontraba en todo el Soconusco e incluso se propagaba hacia Oaxaca. Como antaño, las noticias y el temor se difundieron a lo largo y ancho de los estados vecinos.

${ }^{51}$ Xavier Sistach, Bandas, enjambres y devastación, pp. 78-79; Antonio Buj Buj, "La plaga de la langosta. Permanencia de un riesgo biológico milenario", en Scripta Nova. Revista Electrónica de Geografía y Ciencias Sociales, vol. XII, núm. 270, agosto de 2008, 4-8.

52 "Sobre el embargo de recuas para conducir maíz a la jurisdicción de Teutila (18051806)”, AGNM, Civil, vol. 1416, exp. 5. 


\section{EL RETORNO DE LOS “ENJAMBRES” Y EL REPROCHE A GUATEMALA}

Al revisar detenidamente las Memorias administrativas de los gobernadores oaxaqueńos, llama la atención que -entre 1851 y 1852 la agricultura estatal experimentó una crisis profunda. Y lo que es peor todavía, fueron años que estuvieron marcados por la "escasez de lluvias”. Quizá por eso, cuando se presentaron las primeras aguas en mayo de 1853, los labradores no dudaron en remover la tierra y sembrar las pocas simientes que resguardaban. Las fuentes refieren que, al cabo de unas semanas, el horizonte verdeó y el ánimo en los pueblos comenzó a recuperarse; no obstante, cuando el peligro parecía conjurado, llegaron repentinamente desde el sureste millones de langostas que en tan sólo quince días devastaron las parcelas que surcaban el distrito de Tehuantepec; peor aún, se posicionaron en muchos campos para reproducirse y depositar en sus entrańas millones de canutos.

$\mathrm{Al}$ igual que cincuenta años atrás, esta plaga se posicionó en varios estados del sureste mexicano: Chiapas, Oaxaca, Tabasco, Campeche y Yucatán. En el caso de Oaxaca, tan pronto se percataron de la presencia del acrídido, el gobernador del estado emitió una instrucción para que las autoridades municipales impidieran "la avivación del insecto y exterminen sus crías lo antes posible”. Las autoridades eclesiásticas, por su parte, respaldaron dicha instrucción y comunicaron a sus feligreses sobre las consecuencias que podría acarrear la plaga - " por las actuales circunstancias de la escasez y demora de la temporada de aguas, y por la situación en que estamos con las sementeras nacientes y en las interesantes labores de los campos"-y los exhortaron a "arrepentirse de sus culpas [...] y desarmar el brazo de la Divina Justicia por medio de plegarias, letanías y preces, y una misa solemne en la que se colocará donde se pudiere el Divinísimo Señor Sacramentado exhortando eficazmente que nos libre de la plaga que nos amenaza”. ${ }^{53}$

53 "Sobre la aparición de una plaga de langosta en los pueblos de la diócesis (1853)", en Luis Castañeda Guzmán, comp., Manuel Esparza, ed., Cordilleras eclesiásticas de Oaxaca, 1820-1880, México, Instituto Nacional de Antropología e Historia, Carteles Editores, 2002, 173-174. 
Cierto es que las autoridades instaron a la población a salir del letargo que años atrás posibilitó la proliferación de la plaga; sin embargo, lo trascendente es que, pese a la experiencia acumulada, los pueblos pasaron por alto estos llamamientos. Tengo la impresión de que dicha omisión no derivó del desconocimiento respecto a los acrídidos, sino de varias circunstancias fortuitas que enfrentaron entre 1851 y 1853 , tales como el brote epidémico de colera morbus, las disputas entre las facciones liberales y conservadoras por el control del gobierno estatal y la vigencia de un ciclo rebelde en los pueblos del Istmo de Tehuantepec y la Mixteca de la Costa. ${ }^{54}$

Compenetrados con estos problemas, las autoridades advirtieron que, ante la falta de acciones para combatir los insectos, las cosechas de 1854 no se lograrían "porque en la primavera habrá de avivarse el canutillo que han depositado las mangas de langosta" y la plaga se extendería por todo el estado causando la "peor ruina económica y social de los últimos ańos". ${ }^{55}$ También invitaron a los pueblos para que informaran oportunamente sobre la presencia de insectos y desplegaran todos los recursos a su alcance para exterminarlos.

Las primeras comunicaciones sobre los estragos causados por artrópodos se dieron entre junio y agosto de 1854 y procedieron de los distritos de Huajuapan, Centro, Miahuatlán, Jamiltepec, Tehuantepec y Yautepec. Al igual que antaño, revelaron la aparición repentina de insectos, los daños en la agricultura, el desamparo de las familias indígenas y el temor generado entre los funcionarios de gobierno. En julio de 1854, por ejemplo, el prefecto del distrito Centro comunicó que en tan sólo unas semanas el Valle de Tlacolula y la Sierra Mixe fueron invadidos por "mangas de langosta que se extendieron entre Tehuantepec y los suburbios de la ciudad de Oaxaca”. El prefecto de Huajuapan, por su parte, alertó que una nube de langosta, de "legua y media en línea recta de oriente a po-

${ }^{54}$ Carlos Sánchez Silva, Indios, comerciantes y burocracia, pp. 44-45.

55 "Circular del gobernador de Oaxaca sobre la situación que enfrenta el campo (1854)", AGEO, Gobernación, Ejutla, Acontecimientos notables, leg. 23, exp. 27; "Recomendación del obispo para contener los daños de plagas y epidemias en Oaxaca (1854)", en Luis Castañeda Guzmán, comp., Manuel Esparza, ed., Cordilleras eclesiásticas de Oaxaca, pp. 176-177. 


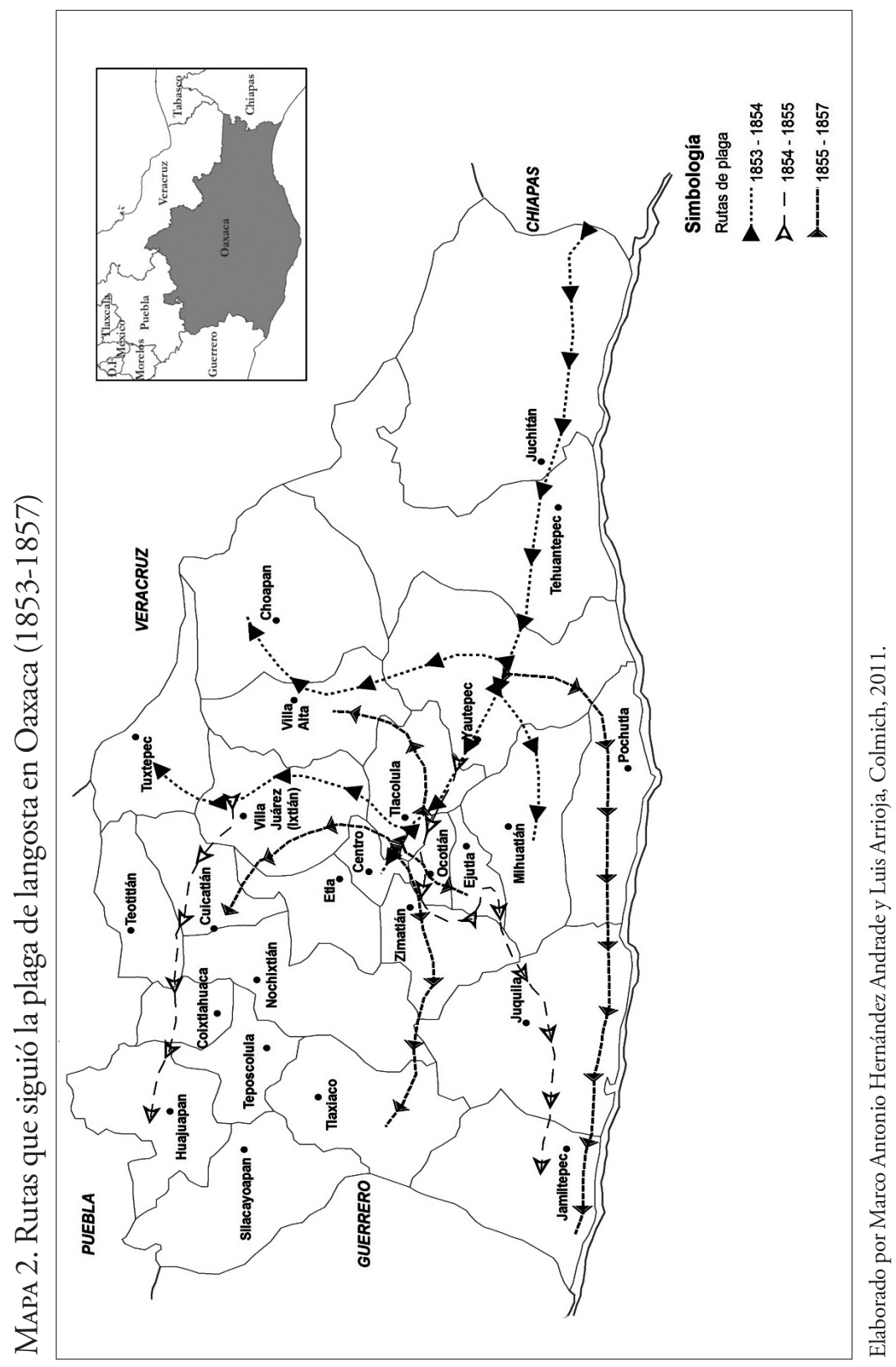


niente y medio cuarto en su latitud de sur a norte", se posicionó en la cabecera distrital y devoró las parcelas y árboles que estaban en las inmediaciones. El prefecto de Miahuatlán anunció que los insectos aparecieron en Santiago Ocotlán por tres días seguidos y en "número muy considerable [...] e invadiendo los terrenos desde las seis de la mañana hasta las doce del día”, dejando daños irreparables en los terrenos agrícolas y "sembrando miedo y agitación entre los ciudadanos" 56 (véase mapa 2).

La plaga no hizo excepción de pueblos, según registran las fuentes; inclusive, aquellas localidades de Tlacolula, Ejutla, Ocotlán y Miahuatlán que históricamente se distinguieron por disponer de tierras de labranza, huertas frutales y haciendas ganaderas se vieron negativamente afectadas por la langosta. En estas mismas fechas, infinidad de pueblos se dirigieron al gobernador del estado para notificarle los problemas de subsistencia que enfrentaban. En la prefectura de Huajuapan revelaron que, ante la escasez de alimentos, la gente estaba ingiriendo plantas y raíces contaminadas con el excremento de langosta so pena de caer enferma. ${ }^{57}$ Se sobreentiende, naturalmente, que estas acciones en busca de alimentos se reprodujeron en otras prefecturas. En todos los casos, pues, la aparición de acrídidos fue el detonante de una crisis de subsistencia en 1854 y que los políticos oaxaqueños denominaron "el año del hambre y la calamidad".

Al tiempo en que las autoridades recibían reclamos de la población e ideaban estrategias para contener la crisis y la plaga, un sector del gobierno se dio a la tarea de buscar explicaciones al respecto. En dicho intento, los argumentos de mayor peso se concentraron en la poca precaución que las naciones centroamericanas tenían en sus campos, ya sea para impedir la anidación de artrópodos o bien para evitar su propagación hacia territorio mexicano. Bajo esta perspecti-

\footnotetext{
${ }^{56}$ Véanse Charles Berry, "La ciudad de Oaxaca en vísperas de la reforma”, en Historia Mexicana, vol. XIX, núm. 1, 1969, 60-61; "Informe sobre la plaga de langosta en la villa de Huajuapan y sus alrededores (1854)", AGEO, Gobernación, Huajuapán, leg. 35, exp. 24, ff. 3-5; Carta del prefecto de Miahuatlán sobre la invasión de langosta en terrenos de Santiago Ocotlán (1854)”, AGEO, Gobernación, Miahuatlán, leg. 24, exp. 2, ff. 3-4.

57 "Recomendaciones para que la gente de la prefectura de Huajuapan eviten el contacto con la plaga de insectos (1854)", AGEO, Gobernación, Huajuapan, leg. 35, exp. 24, ff. 7-8.
} 
va, los políticos oaxaqueños no tardaron en lanzar diatribas contra países vecinos. En mayo de 1854, por ejemplo, advirtieron que:

innumerables bandas de insectos destructores que de la América Central se dirigían a nuestro territorio devorando todo a su paso y amenazando con los horrores del hambre a los pobladores infelices de las localidades invadidas, arrancaron en Tehuantepec un grito de alarma que difundió el terror en diversos lugares de la República. Desde esa época, las comunicaciones oficiales no han dejado de anunciar desgracias continuadas, presagiando aún otras mayores, pues desde entonces también estos enemigos de nueva especie han derramado en muchas direcciones, llevando consigo la desolación y la miseria. ${ }^{58}$

Un mes después, el reproche subió de tono y precisó que "alguna localidad de esta nación de Centroamérica es la cuna del insecto, pues no se sabe que la nación entera la produzca”. Hacia julio de 1854, los políticos oaxaqueños focalizaron sus recriminaciones e incluso aseguraron que en una porción de Guatemala se "había violentado la emigración [del insecto] consecuencia de que aumentando el número de estos animales de un modo exorbitante, los labradores que allí iban a sembrar su algodonales tuvieron que incendiarle para consumirlos, más como eran ya en edad adulta emprendieron sus correrías". ${ }^{59}$ Inclusive, dichas correrías fueron documentadas por el viajero alemán Gustav Von Tempsky a su paso por los partidos de Verapaz, Chimaltenango, Suchitepequez, Quetzaltenango, Soconusco y Tehuantepec. ${ }^{60}$

Habrá que subrayar que los reclamos no se lanzaron únicamente por considerar a Guatemala un país donde anidaba la langosta

${ }^{58}$ Manuel Ortega Reyes, "La langosta”, en Boletín de la Sociedad Mexicana de Geografia y Estadistica, tomo IV, 1857, 353.

${ }_{59}$ Manuel Ortega Reyes, "La langosta", en Boletín de la Sociedad Mexicana de Geografía y Estadistica, tomo IV, 1857, 354. Para contrastar la opinión de los políticos oaxaqueńos y vislumbrar el alcance que tuvo la plaga de langosta en Guatemala durante estos años, véanse David McCreery, Rural Guatemala, 1760-1940, Stanford, Stanford University Press, 1994; Julio Castellanos Cambranes, Café y campesinos en Guatemala, 18531897, Guatemala, Editorial Universitaria, 1983.

${ }^{60}$ Gustav von Tempsky, Mitla. A narrative of incidents and personal adventures on a journey in Mexico, Guatemala, and Salvador in the years of 1853 to 1855. With observations on the modes of life in those countries, editado por J. S. Bell, Londres, 1858, 299-301. 
sino por tratarse de un momento coyuntural de conflictos diplomáticos entre ambos países, ya sea por los límites fronterizos, invasiones territoriales o posturas políticas divergentes: por un lado, México preparando el escenario de una reforma liberal y, por otro, Guatemala restaurando los viejos privilegios e impuestos coloniales. Además de estos hechos, los políticos oaxaqueños también visualizaban a Guatemala como una nación que, desde principios del siglo XIX, desplazó el principal rubro de la economía -la grana cochinilla- de los mercados internacionales debido a que el

nopal que alimentaba el insecto se cultiva en Guatemala desde hace varias décadas $[. .$.$] o porque en esas tierras se produce más tinte [...] lo que ha$ sumido los valores de este artículo en nuestro comercio [...] y dejado de costear al indio en su trabajo [...], al grado que hoy este negocio se reduce a un pequeño porcentaje de lo que antiguamente era. ${ }^{61}$

Cualquiera que haya sido el caso, lo cierto es que para estas fechas el gobierno oaxaqueño desconocía la naturaleza de la plaga que azotaba sus campos, carecía de recursos para combatirla, y-peor aún- excusaba su propagación en una cuestión político-económica. Ante esto, cabe preguntarse ¿Qué derrotero tuvo este fenómeno natural después de 1854 ?

\section{Remedos Antiguos y ATISbos De Ciencia}

Hacia mediados de 1855, la plaga de langosta continuaba presente en los pueblos de Oaxaca. Por si esto no fuera suficiente, las tem-

${ }^{61}$ Memoria que el gobernador del estado presenta al primer congreso constitucional de Oaxaca en sus sesiones ordinarias de 1858, Oaxaca, Imprenta de Ignacio Rincón, 1858, 19-20. Aunado a la crítica que generaba la competencia mercantil en el ramo de la grana cochinilla, habrá que sumar el hecho de que las tropas guatemaltecas - por instrucciones del general Rafael Carrera- invadieron temporalmente parte del territorio de Chiapas con el objeto de reclamar el territorio de Soconusco, situación que generó un problema diplomático con México. Véase "Agresión de Guatemala (1853)", en Obras completas de Francisco Zarco, vol. IV. Periodismo político y social 4, México, Centro de Investigación Científica Jorge L. Tamayo, 1990, 142-145; “La agresión de Guatemala (1853)”, en Obras completas de Francisco Zarco, vol. v. Periodismo politico y social 5, México, Centro de Investigación Científica Jorge L. Tamayo, 1990, pp. 120-125. 
peraturas cálidas de ese año reactivaron el ciclo biológico de los ortópteros e incluso lo expandieron hacia aquellas zonas donde aparentemente se había erradicado. Así, el prefecto de Miahuatlán, importante zona agrícola y ganadera del estado, informaba en el verano de 1855 que los campos y sembradíos de la villa de Ejutla se encontraban devastados por la langosta; no obstante, advertía que en el intento de proteger sus sementeras, la población exterminó y enterró aproximadamente quinientas arrobas de artrópodos. Desde las prefecturas de Tehuantepec y Yautepec, algunos pueblos reportaron la destrucción de 300 y 400 arrobas en tan sólo una semana. ${ }^{62}$ Tal vez estas cifras parezcan insignificantes por sí mismas; sin embargo, conviene decir que en su conjunto representaron aproximadamente 13,800 kilogramos de acrídidos que en un solo día llegaban a consumir la equivalencia de su peso, algo así como exterminar la cubierta vegetal de un terreno de dos hectáreas.

Obviamente, estos hechos provocaron una cadena de problemas en las localidades, pues los insectos solían roer las hojas, flores, frutos, simientes, cortezas, plantas, árboles y todas las especies vegetales que encontraban a su paso. Si bien, la gente trató de remediar esto aprovechando al máximo sus reservas agrícolas y animales, también es cierto que dicha estrategia acarreó algunas desventajas. En los pueblos de la prefectura de Yautepec, por ejemplo, los pastos escasearon progresivamente y las cabezas de ganado vacuno padecieron la falta de alimento y la enfermedad. De ahí, entonces, que el prefecto refiriera en julio de 1855 que "no ha sido posible exterminar dicha plaga, pues está lejos de desaparecer y se presenta cada día con más abundancia casi en todos los pueblos [...] habiendo cabido hasta hoy la infelicidad [...] de tan dańino animal [...] que devora las plantas [...], enferma los animales $[. .$.$] y mata de hambre a la gente". { }^{63}$

Tal vez los alcances y la gravedad de la plaga pueda medirse por las recurrentes procesiones y misas que se realizaron a lo largo del estado durante 1855 . De esta manera, no es casualidad que los pá-

62 "Sobre la destrucción de 500 arrobas de langosta en la villa de Ejutla (1855)", AGEO, Gobernación, Miahuatlán, leg. 24, exp. 3, f. 1.

63 "Informe del prefecto de Yautepec sobre la dificultad de erradicar la plaga de langosta (1855)", AGEO, Gobernación, Yautepec, leg. 15, exp. 1, ff. 3-4. 
rrocos de Zacatepec y Tezoatlán -en la prefectura de Huajuapancelebraran misas y rogaciones cada tercer día para que "los enjambres de insectos desaparezcan y dejen de atemorizar al vecindario", que los feligreses de la ciudad de Oaxaca caminaran por las calles con el señor Sacramentado y la virgen del Carmen para rogar soluciones inmediatas, que el prefecto de Villa Alta instara a los ciudadanos a implorar la corte celestial para "detener los funestos resultados de la plaga” y que el ayuntamiento de Huajuapan destinara recursos públicos para celebrar procesiones, misas y rogaciones al señor de los Corazones con el objeto de que "esta villa reciba los beneficios espirituales y se acabe la plaga lo antes posible". ${ }^{64}$

Otros hechos que revelan los problemas que acarreaban las plagas son los brotes de violencia en los pueblos. En noviembre y diciembre de 1855, por ejemplo, se levantaron en armas los vecinos de San Sebastián Coatlán y San Bartolomé Loxicha contra el prefecto de Miahuatlán, a quien acusaron de acumular las reservas de maíz de la jurisdicción, especular con los precios de las simientes, exigir el pago de contribuciones y desatender las urgencias de la población que "está siendo afectada por una fiebre maligna [...] y una plaga de langosta que destroza los cultivos" ${ }^{65}$ Hechos semejantes se reportaron en las prefecturas de Yautepec, Tehuantepec y Tlacolula. Tal vez lo más trascendente de esto estriba en que los pueblos exigían una respuesta eficaz del gobierno ante los daños que acarreaban los insectos, mientras que las autoridades prestaban la mínima atención sobre el fenómeno natural e incluso continuaban cobrando impuestos.

Movidos por estas presiones, los gobernantes oaxaqueńos decidieron invertir recursos para entender el fenómeno de la plaga y -en su momento- desplegar las medidas para erradicarla. En este contexto, afortunadamente, el aparato científico encargado de asesorar

64 "Órdenes y acciones libradas en las parroquias de Zacatepec y Tezoatlán para contener la plaga (1855)", AGEO, Gobernación, Huajuapan, leg. 35, exp. 26, ff. 1-2; "Oficios del prefecto de Villa Alta sobre la invasión de una plaga de langosta (1855)”, AGEO, Gobernación, Villa Alta, Acontecimientos notables, exp. 11, f. 2; "Medidas para detener el avance de la plaga de langosta (1855)", Archivo Histórico Municipal de Huajuapan de León (en adelante AHMH), Actas de cabildo, libro de 1855, ff. 3-4.

65 "Informe sobre los levantamientos en Coatlán y Loxicha (9 de diciembre de 1855)”, AGEO, Gobernación, Miahuatlán, leg. 23, exp. 16, f. 1. 
al gobierno se encontraba en pleno auge. Según Perla Chinchilla, con la creación del Ministerio de Fomento en 1853 se emprendieron numerosos proyectos que buscaron solucionar los problemas que afectaban a la nación, en general, y los estados, en particular. ${ }^{66}$ Penoso y áspero fue el camino de estos proyectos por las condiciones del periodo 1853-1857, no así los conocimientos científicos generados. Prueba de ello fue la Escuela Nacional de Agricultura, una institución que formó a los primeros estudiosos del campo mexicano y que proveyó aportes trascendentes sobre el conocimiento del reino animal y vegetal en México.

Fue precisamente en la Escuela Nacional de Agricultura donde el gobernador oaxaqueño, Benito Juárez García, buscó ayuda para entender y combatir la plaga que azotaba el estado. Según las fuentes, el plantel recibió su petición en junio de 1856 e inmediatamente tomó cartas en el asunto, para lo cual comisionó a los profesores Julio Lavarriere Varela y Pío Bustamente y Rocha con el objeto de elaborar un "dictamen sobre la aparición de la langosta" en Oaxaca y trazar un plano que "de una idea de la marcha que ha seguido el pernicioso insecto que es tan importante destruir". ${ }^{67}$

En lo que respecta al dictamen, las fuentes confirman que fue elaborado en tan sólo tres meses con la información recopilada en campo, la escasa bibliografía científica y los testimonios de tres políticos que -entre otras cosas- experimentaron in situ las calamidades del acrídido: Ignacio Goytia, Rafael Vaquerizo y José Antonio Nieto. Como era de esperarse, se trató de un dictamen muy general que recopiló reflexiones, argumentos y técnicas para prevenir y combatir la

${ }^{66}$ Perla Chinchilla, "Introducción”, en Elías Trabulse (coord.), Historia de la ciencia en México. Siglo XIX. La ciencia mexicana del periodo nacional, México, Fondo de Cultura Económica, 1985, 10.

67 "Dictamen sobre la langosta presentado por la Escuela Nacional de Agricultura (1856)”, en Antonio Márquez Delgado, La lucha contra la langosta en México, p. 84. Se tiene conocimiento que Lavarriere y Bustamante fueron dos admiradores de Linneo, se distinguieron por conocer y difundir las obras de Lamarck en México y se encargaron de dictar las cátedras de zoología y botánica en la Escuela Nacional de Agricultura; asimismo, se sabe que pertenecieron a la Sociedad Mexicana de Geografía e Historia y que sirvieron como asesores del Ministro de Fomento, Joaquín Velásquez de León. 
plaga. ${ }^{68}$ Dicho documento iniciaba seńalando que la langosta encontrada en Oaxaca era una especie completamente diferente del Acridium mygratourius del que hablaban el biólogo francés Charles Victor d' Orbigny en el Dictionnaire universel d'histoire naturelle... (1849) y el viajero irlandés William Bowles en el Semanario de Agricultura de Madrid... (1802); también afirmaron, con vocación lamarckiana, que la única característica que compartía este acrídido con el observado en Europa era que se trataba de un insecto propio de "países cálidos, que se reproduce con bastante regularidad y en número suficiente para hacerse temible en los lugares cuya temperatura se mantiene a un grado elevado durante muchos años" (p. 86); inclusive, describieron algunos hábitos del insecto que -a la postre- los llevaría a comprender los orígenes de la plaga y corroborar una tesis de Lamarck:

mientras la langosta del antiguo mundo extiende sus estragos [...] de un modo desordenado, la especie americana parece seguir leyes más regulares [...] pues es una tradición general [...] que se propague cada cincuenta ańos [...]; los ancianos refieren con amargura los daños causados en Tehuantepec y Oaxaca en 1804 [...]; casi cincuenta ańos después se ha vuelto a presentar en las mismas localidades (p. 86).

Sobre esto último, conviene recordar que los conocimientos científicos sobre la flora y fauna en México se apoyaban en razonamientos de Bonnet, Diderot, Linneo y Lamarck. En lo que respecta a Lamarck, se conocía y estudiaba la Philosophie zoologique, ou exposition des considérations relatives a l'histoire naturelle des animaux... (1809) un tratado que planteaba la influencia del clima en los seres vivientes y proponía dicho factor como el eje modificador de hábitos, necesidades, influjos y defectos de los animales. ${ }^{69}$ Dado esto no es casualidad que los comisionados se inspiraran en dicha Philoso-

${ }^{68}$ Ignacio Goytia se desempeñó como gobernador de Oaxaca en tres ocasiones: 1836-1837, 1839-1841 y 1846; Rafael Vaquerizo fungió como agente del Ministerio de Fomento en el Istmo de Tehuantepec entre 1854 y 1855.

${ }^{69}$ Sobre la influencia del pensamiento de Lamarck en México, véase Enrique Beltrán, Lamarck. Interprete de la naturaleza, México, Talleres Gráficos de la Nación, 1945, 44-48, 114-116. 


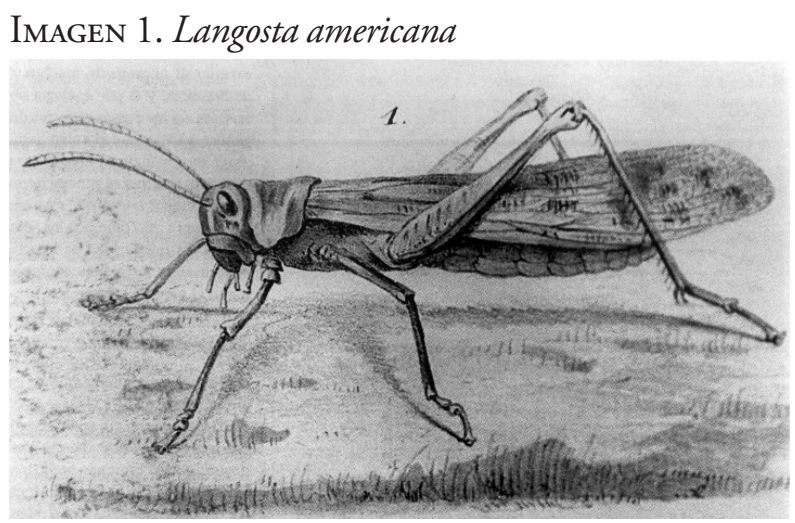

Tomada de Manuel Ortega Reyes, "La langosta", en Boletín de la Sociedad Mexicana de Geografia y Estadística, tomo Iv, 1857.

phie para considerar que la plaga de langosta hallada en Oaxaca tenía su foco de gestación en la América Central y su espacio de multiplicación en el sureste mexicano, pues desde su perspectiva:

allá se multiplica durante cierto tiempo [...] y luego llega y permanece en tanto que la nueva generación, unida a la antigua, encuentra condiciones favorables y medios para alimentarse; pero llega un momento en el que aumentando el número de individuos en proporción inversa de los recursos alimenticios, éstos faltan y entonces comienzan las emigraciones en masa que hoy nos afligen [...] Resulta, pues, de lo dicho que sin duda por influencia del clima, y a causa de una vegetación más conveniente a su desarrollo [en territorio oaxaqueño], la langosta vivifica rápido [...] y pronto llega al periodo en que es llamada voladora. ${ }^{70}$

Bajo estas premisas, Lavarriere y Bustamante advirtieron que los métodos más eficaces para erradicar la plaga eran los preventivos más no los combativos. Siendo así, señalaron la necesidad de conocer los territorios endémicos de la especie, los hábitos que tenía en sus diferentes estadios, las funciones que cumplía en su entorno y las

70 "Dictamen sobre la langosta presentado por la Escuela Nacional de Agricultura (1856)”, en Antonio Márquez Delgado, La lucha contra la langosta en México, pp. 87, 91. 
características de su ciclo biológico. Conviene hacer constar que estas sugerencias también sirvieron para lanzar una crítica contra el gobierno oaxaqueño por desconocer el fenómeno natural que afectaba el estado y perder el tiempo en "prescribir la práctica de los medios indicados por el reglamento del Consejo de Castilla, confundiendo la langosta de Espańa con la de América, no obstante que difieren esencialmente en su exterior y hábitos" (p. 87).

Inspirados en el pensamiento evolucionista, los comisionados plantearon que los insectos hallados en Oaxaca eran del orden ortóptero, diferían de los observados en Europa por su tamańo y color, al grado que algunos llegaban a medir entre cuatro y diez pulgadas de longitud y dos pulgadas de diámetro, y que las

primeras bandadas de langosta que se presentaron en Oaxaca estaban formadas de insectos de tamaño y color uniformes, siendo esta una mezcla de amarillo y encarnado [...], pero luego se observaron ya diferencias notables: la langosta más nueva era enteramente amarilla [...], a la edad intermedia tomó un tinte más rojo [...] y en cuanto a la adulta su color era más oscuro (p. 89).

La literatura científica reciente confirma estas observaciones y atribuye dichos cambios a una concentración de pigmentos en los insectos que resulta de una evolución selectiva de la especie. ${ }^{71}$

Enseguida, Lavarriere y Bustamante examinaron las características de crecimiento y las condiciones ambientales que favorecían la propagación del insecto. De lo anterior concluyeron que este acrídido arribó a Oaxaca en junio de 1853, fecha en que comenzó su ovación en terrenos poco arcillosos y relativamente calientes, como los ubicados en las prefecturas de Tehuantepec y Yautepec; al paso de tres meses, los insectos crecieron, migraron y reprodujeron su

71 "Dictamen sobre la langosta presentado por la Escuela Nacional de Agricultura (1856)”, en Antonio Márquez Delgado, La lucha contra la langosta en México, p. 89. También véase Jeffrey Lockwood, Locust. The Devasting Rise and Mysterious Disappearance of the insect that Shaped the American Frontier, Nueva York, Basic Books, 2004, 46-47; R. F. Chapman, The Insects. Structure and Function, Cambridge, Harvard University Press, 1982, 657-674. 


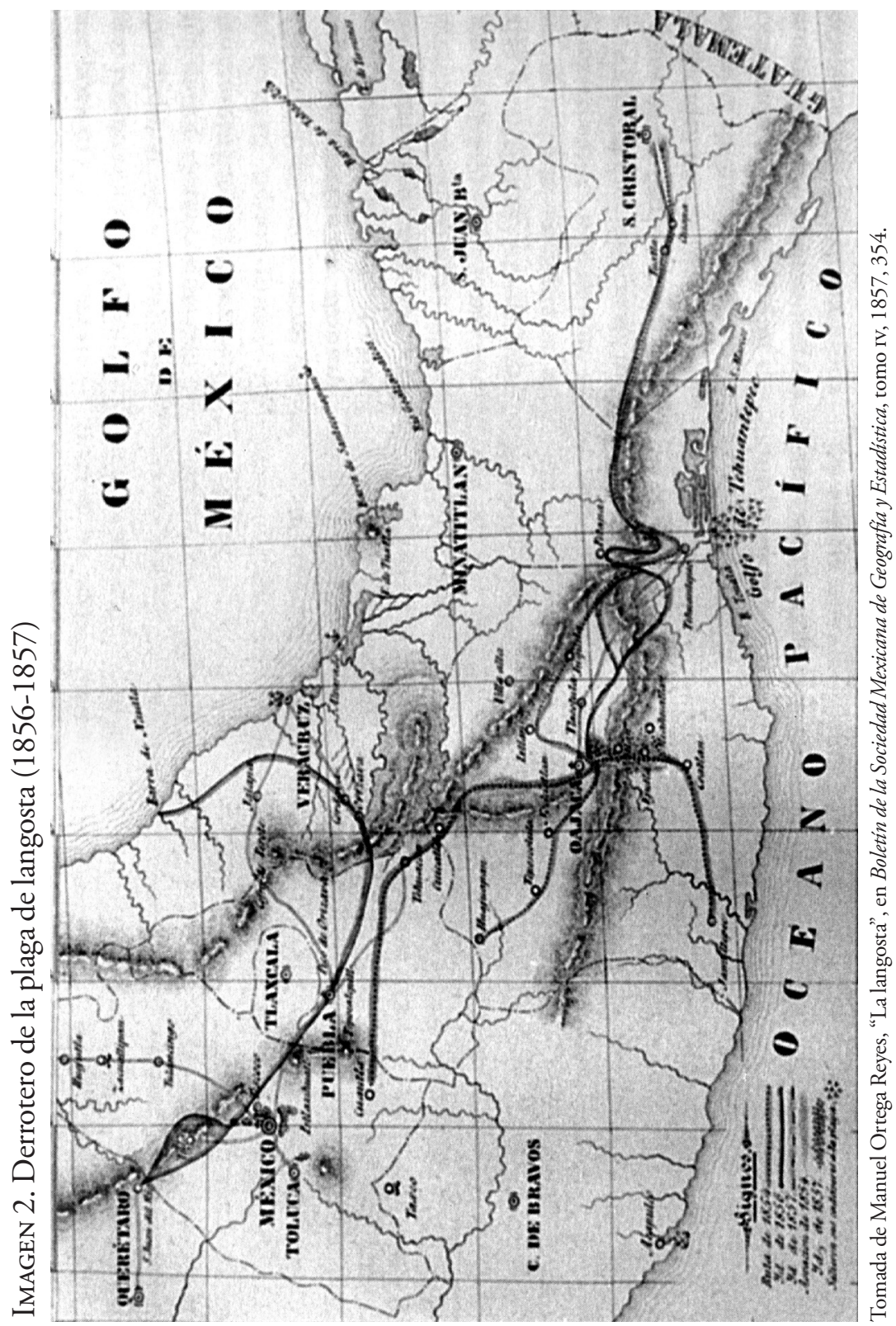


ciclo biológico en otros espacios. Con esta perspectiva, sugirieron un tópico muy innovador para erradicar la condición gregaria del artrópodo: el uso de insectos depredadores y repelentes naturales. En cuanto a los depredadores, mencionaron la urgencia de conocer e incluso manipular el ciclo biológico de un "animalillo con el cuerpo blanco y la cabeza negra [...] que se posiciona en el saltón y lo aniquila lentamente". A juzgar por la literatura reciente, Lavarriere y Bustamante se referían a una larva que era parasitada por una variedad de insectos dípteros - como moscas o mosquitos- en el lomo o vientre de la langosta. Dicha larva se hospedaba en el acrídido hasta perforar su piel y alojarse en sus cavidades; enseguida, se alimentaba de la hemolinfa -sangre del insecto- hasta deshidratarlo y terminar con su vida. ${ }^{72}$ Sobre los repelentes naturales, recomendaron usar tres variedades de plantas: tomillo (Thymus), serpóleo (Thymus serphilium) y ruda (Ruta graveolens) que preparándolas como ungüento en la madera y prendiéndole fuego se generaba una "cortina de humo oloroso" que disolvía los enjambres de insectos y los "hace chocar contra los obstáculos naturales que encuentran en su vuelo, precipitándolas a tierra” (p. 92).

Posteriormente, examinaron el derrotero que siguió la langosta desde 1853 hasta 1856 . Con esto en mente, subrayaron que la plaga llegó procedente de Guatemala y tomó dos rumbos: una hacia Petapa y otra hacia Tehuantepec. Sobre el segundo derrotero, advirtieron que la plaga irrumpió, primeramente, en el Soconusco y, posteriormente, se "dirigió al departamento de Oaxaca [...] por la inmensa porción de tierra baja que se extiende desde Tehuantepec hasta los confines de Veracruz y Tabasco" (p. 93). Desde su perspectiva, esto provocó que, en tan sólo tres meses, las prefecturas del Centro, Tlacolula, Teotitlán del Camino, Ixtlán, Villa Alta, Choapam, Jamiltepec, Yautepec, Huajuapan y Cuicatlán fueran atacadas por los

${ }^{72}$ Xavier Sistach, Bandas, enjambres y devastación, p. 330; D. J. Boucias y J. C. Pendland, Principles of Insects Pathology, Boston, Kluber Academic Press, 1998, 203-204. Para estas mismas fechas, la comisión entomológica de los Estados Unidos desarrolló métodos semejantes para manipular el ciclo biológico de insectos con el objeto de combatir la plaga de langosta que se posicionó sobre las montañas rocallosas. Véase W. Conner Sorensen, Brethren of the Net. American Entomology, 1840-1880, cap. 7. 
insectos. Sembrada la calamidad en el estado, los animales migraron hacia Guerrero, Puebla, Morelos y Veracruz (véase imagen 2).

La proclividad de los comisionados con el evolucionismo lamarckiano los llevó a plantear que estas migraciones respondían a una necesidad biológica de los insectos: encontrar mayores bastimentos de comida y mejores condiciones ambientales de reproducción; de ahí que "durante el invierno y parte de la primavera se internaran en tierras fértiles y ricas no sujetas a la estación rigurosa y allí permanecieron hasta que la estación se suavizó y la vegetación se renovó, y entonces, excitadas por la temperatura, se dirigieron poco a poco a las regiones de clima templado" (p. 95).

Resulta pertinente notar que el dictamen finalizó con una instrucción para combatir la plaga que, entre otras cosas, retomaba las consideraciones planteadas en los ordenamientos coloniales de 1803 y 1804 . Tal vez lo más sugerente de la nueva instrucción radicó en plantear un discurso encaminado a prevenir la condición gregaria de los insectos y evitar por todos los medios la formación de plagas. En este entendido, la instrucción se integró por seis puntos. Los dos primeros correspondieron a las obligaciones del gobierno para recabar recursos que permitieran concientizar a la población sobre la plaga, exterminarla en caso de su desarrollo y gratificar a los ciudadanos que participaran activamente en dicha labor. Los puntos tres y cuatro delimitaron las sanciones para autoridades y ciudadanos que descuidaran las tareas precautorias y combativas del insecto. Los últimos dos puntos fueron los más extensos y se ocuparon propiamente de las responsabilidades del gobierno -federal, estatal y municipal- para prevenir y exterminar la langosta.

En general, este dictamen puede leerse como un avance en el conocimiento científico que se tenía sobre las plagas de langosta en México. Es evidente que los autores proporcionaron datos innovadores sobre la naturaleza del acrídido y sus diferentes conductas en la fase endémica; inclusive, la observación in situ y la recopilación de testimonios les posibilitó trazar los derroteros de la plaga; tal vez lo más destacado radica en los argumentos que plantearon sobre el influjo del clima en los insectos, las mutaciones físicas de la especie y, sobre todo, la existencia de microorganismos larvarios que más 
allá de actuar como depredadores fungían como barreras ecológicas de la plaga.

A juzgar por la documentación, este dictamen inspiró tanta confianza en las autoridades que el ministro de fomento, Manuel Siliceo, señaló en 1857 que el documento era una guía para que la república "logre ver libres sus siembras [...] de los ataques del voraz insecto". ${ }^{73}$ No obstante, debo advertir que en el sureste mexicano dicha guía no pudo instrumentarse y mucho menos contuvo el instinto devorador de los acrídidos.

Al centrar la atención en Oaxaca, todo parece indicar que -entre 1856 y 1857- la plaga continuó vigente. Dicho vigor se ancló en las condiciones climáticas que favorecieron el ciclo biológico del insecto, las pocas acciones para restringir la propagación de la plaga y, sobre todo, la escasez de energía humana para contrarrestar la voracidad de los bichos. Sobre esto último, debo subrayar que, entre febrero y octubre de 1857, las prefecturas de Centro, Huajuapan, Jicayán, Miahuatlán, Tehuantepec, Yautepec y Villa Alta fueron declaradas en alerta por la irrupción y propagación de una enfermedad de corte epidémico: el cólera morbus.

Ante este escenario tan desolador, los políticos oaxaqueños no dudaron en formular argumentos para explicar lo que sucedía. En su desesperación, lanzaron cualquier tipo de diatribas contra los pueblos hasta llegar a considerarlos como culpables de esta calamidad. En abril de 1857, por ejemplo, las autoridades de Yautepec advertín que la plaga se mantenía presente en el distrito debido al rechazo que "formulan los pueblos de dividir sus tierras comunes y fomentar que los individuos migren a los parajes incultos", situación que -desde su perspectiva- impedía "perseguir a los insectos en aquellos terrenos desolados y montuosos". ${ }^{74}$ Un mes después, las autoridades de Villa Alta señalaron que la plaga seguía causando estragos en las parroquias

${ }^{73}$ Memoria de la Secretaría de Estado y del despacho de Fomento, Colonización, Industria y Comercio de la República Mexicana escrita por el Ministro de Fomento, C. Manuel Siliceo, para dar cuenta de ella al Soberano Congreso Constitucional, México, Imprenta de Vicente García Torres, 1857, 69.

74 "Sobre las secuelas que ha provocado la plaga de langosta en los pueblos de Yautepec (1857)”, AGEO, Gobernación, Yautepec, leg. 15, exp. 3. 
de Puxmetacán, Atitlán y Totontepec debido a que era imposible practicar las medidas dictadas para destruir el insecto "por ser aquellos terrenos en extremo montuosos [...] así como por la conducta que tienen demostrada los indígenas que ven todo esto con la mayor indiferencia sin considerar su muerte futura". ${ }^{75}$ En septiembre del mismo año, las noticias recibidas desde Huajuapan indicaron que muchos localidades eran afectadas por la langosta debido a la negativa de cumplir con los mandatos oficiales y rehusarse "a la quema o matanza de aquel animal porque se les ha hecho concebir la triste idea de que si lo matan les sobreviene tabardillo" ${ }^{76}$

Conviene señalar que tanto las autoridades oaxaqueñas como los comisionados de la Escuela Nacional de Agricultura también inspiraron una serie de reproches. En esta ocasión, la Sociedad Mexicana de Geografía y Estadística -a través del doctor Manuel Tort - señaló que la plaga que azotaba el campo oaxaqueño tenía sus orígenes en la naturaleza misma y en la voracidad del Acridium mygratorium y no en los "sujetos o lugares que indican los gobernantes de Oaxaca"; dicha Sociedad también se pronunció sobre el dictamen de la Escuela Nacional de Agricultura, planteó dudas sobre su elaboración y advirtió la urgencia de aclarar la exactitud de la plaga:

ya que de esto dependerá sin duda alguna, que sean más acertadas y económicas las medidas que puedan tomarse con el fin de evitar o disminuir los efectos destructores de esta plaga [...]; y porque debemos fijarnos sobre lo que tenga más inmediata utilidad práctica, comparando todo lo que sobre este particular se ha escrito [...], porque si efectivamente el desarrollo de este insecto es tan precoz como se asienta, es claro que las medidas aconsejadas por los autores para evitar o disminuir el crecimiento y desarrollo de la langosta [...] no serán aplicables, o en caso de serlo se han de poner en acción con mucha más violencia, por el cortísimo tiempo que media entre la ovación y el crecimiento. ${ }^{77}$

75 "Oficios del gobernador de Villa Alta sobre la invasión de una plaga de langosta (1857)”, AGEO, Gobernación, Villa Alta-Acontecimientos naturales, leg. 3, exp. 13, f. 1.

76 "Sobre la negativa de los pueblos a exterminar la langosta (1857)", AGEO, Gobernación, Huajuapan, leg. 35, exp. 24, f. 17.

${ }^{77}$ José María Tort, "Dictamen de la comisión nombrada para abrir el dictamen sobre 
Por suerte, al tiempo en que la Escuela Nacional de Agricultura y la Sociedad Mexicana de Geografía y Estadística se enfrascaban en pronunciamientos y reproches, las noticias sobre la plaga comenzaron a escasear y, prácticamente, desaparecieron hacia el verano de 1858. Paradójicamente, durante el primer semestre de ese año, la Secretaría del Despacho del Gobierno de Oaxaca fue invadida por comunicados que referían la concurrencia de lluvias y descensos bruscos de temperatura. Sobra decir que estos datos corroboraron, con el paso de los meses, una crisis en la condición gregaria de los insectos, una nueva alteración en las condiciones climáticas y-de alguna manera- una vigilia para las tierras cultivables en lo que se refiere a plagas de insectos.

\section{Comentarios finales}

A lo largo del texto he tratado de plantear las circunstancias que propiciaron el surgimiento y la evolución de dos plagas de langosta en el territorio del actual estado de Oaxaca (1802-1804 y 18531857). Con esto en mente, he señalado que las plagas cobraron sentido al tiempo en que una población de acrídidos experimentó cambios en su sistema endocrino, se reprodujo masivamente, migró en busca de espacios que le permitieran saciar su apetito y perpetuar su condición endémica. En estas migraciones, los insectos se posicionaron sobre territorios, extensos abatieron cuanta cubierta vegetal encontraron a su paso, alteraron los ecosistemas donde pulularon y socavaron los recursos alimenticios de sociedades eminentemente agrarias.

Con esto en mente, he examinado la visión que tenían los gobernantes y los pueblos indios de Oaxaca en torno a las plagas de langosta y, con ello, he tratado de vislumbrar que se trataba de una perspectiva heredada de la Colonia y muy cercana a la que tuvieron los virreyes Berenguer de Marquina e Iturrigaray Aréstegui. Si hubiera que agruparla o clasificarla, con ninguna encajaría mejor,

la memoria relativa a la langosta (1858)", en Boletín de la Sociedad Mexicana de Geografía y Estadistica, tomo vi, 1858, p. 154. 
puesto que con ella coincide en todo lo fundamental: las plagas eran entendidas como desastres de la naturaleza o castigos divinos que aparecían repentinamente, sembraban temor entre la población y causaban daños irreparables en el campo al grado de suscitar crisis agrícolas.

Tal vez la persistencia de esta visión radicó en el contacto continuo de las sociedades con dicho acrídido y en el predominio de ideas relacionadas con la decadente escolástica, en las cuales se confundía el fenómeno de las plagas con los resultados que acarreaban. Dado esto, no es extrańo que los bandos, instrucciones y reglamentos emitidos entre 1802 y 1853 reconocieran que el problema de estas calamidades eran los dańos causados en las tierras de cultivo el uso de técnicas combativas y la proscripción de la especulación. Como era de esperarse, esta visión no sólo impidió formular acciones preventivas al respecto sino también posibilitó que los acrídidos reprodujeran a diestra y siniestra su ciclo biológico y potenciaran su condición gregaria. Por consiguiente, las plagas de 1802-1804 y 1853-1857 fueron lo suficientemente duraderas como para sembrar el temor entre la población, captar la atención y los recursos del Estado, y abatir la producción agrícola de las zonas afectadas. Obviamente, existieron circunstancias ajenas a los insectos que potenciaron su condición endémica. Una de ellas fue la accidentada geografía oaxaqueña que posibilitó a los acrídidos encontrar espacios de alimentación, refugio, reproducción y anidación que estaban fuera del alcance humano. La otra, fueron las ancestrales prácticas agrícolas de prolongar los barbechos de tierras cultivables hasta por diez o doce años, según la ubicación de las superficies; situación que imposibilitó la remoción de suelos y la destrucción periódica de canutos. Debo mencionar que esta situación no fue privativa de los pueblos indios, pues los testimonios del gobierno estatal revelan que esta misma problemática experimentaron las pocas haciendas que existían en el Istmo de Tehuantepec, los Valles Centrales, la Cañada y la Mixteca.

A pesar de estas circunstancias, los pueblos indios de Oaxaca no dudaron en desplegar técnicas ancestrales para proteger cosechas, preservar simientes y garantizar el acceso a los recursos agrícolas. Si 
bien es cierto que estas acciones buscaban erradicar la calamidad natural como diera lugar, también es verdad que los resultados obtenidos no sólo fueron formales sino infructuosos. Lo más interesante de estos hechos radica en que evidenciaron, por un lado, la preocupación de los pueblos frente a fenómenos naturales difíciles de controlar y, por otro, la capacidad para destinar recursos que estuvieran a su alcance con el objeto de proteger sus tierras, contener la proliferación de insectos y abatir el desabasto de granos.

Hasta donde puede distinguirse, estas acciones e ideas persistieron hasta 1856 , fecha en que las autoridades comenzaron a difundir -con ayuda de las sociedades científicas- que las plagas no sólo eran "perniciosas" y "enemigas de la nación", sino también pruebas fehacientes del influjo que tenían las condiciones ambientales sobre el reino animal y vegetal. También plantearon el argumento de que estos fenómenos eran peligrosos siempre y cuando la población no dispusiera medidas para conocer los insectos y contener su fase gregaria. Como seńalé arriba, estos conocimientos se alcanzaron cuando el gobierno de Oaxaca solicitó la intervención de la Escuela Nacional de Agricultura para estudiar y contener la plaga que azotaba el estado. En efecto, los comisionados Lavarriere y Bustamante probaron con rigor científico que las plagas de acrídidos eran periódicas, respondían necesariamente a cambios bruscos en las condiciones ambientales, seguían rutas relativamente estables y condicionaban su existencia en tres factores: temperaturas estables (de preferencia cálidas y semihumedas), disponibilidad de terrenos con abundante vegetación y, sobre todo, inexistencia de medidas preventivas.

Pese a los conocimientos generados por Lavarriere y Bustamante, las plagas de langosta persistieron en el estado. Desde la perspectiva de las autoridades, esto era producto de la poca atención que brindaban las naciones vecinas a la proliferación de la Schistocerca americana en sus tierras y su posterior propagación a territorio oaxaqueńo, así como la negativa de los pueblos indios a instrumentar la normatividad emitida por el gobierno; desde la postura de los pueblos, dichas plagas continuaban presentes debido a la escasez de recursos para enfrentarlas y la negativa de algunos sectores de la 
población para exterminar los insectos. Sea de ello lo que fuera, lo cierto es que las plagas de 1802-1804 y 1853-1857 fueron duraderas debido a la escasez de acciones que previnieran la anidación y evolución biológica de los acrídidos; asimismo, habrá que considerar la dificultad de los pueblos para roturar las tierras cultivables que se esparcían por una geografía sumamente accidentada y la desorganización en los sistemas de prevención debido a la epidemia de cólera.

Para suerte de las autoridades y los pueblos, los descensos bruscos en la temperatura y las lluvias torrenciales de 1857 y 1858 rompieron el ciclo biológico del insecto y contuvieron su voracidad sobre el campo oaxaqueño. No obstante, este sosiego se prolongó tan sólo dos décadas ya que

las calamidades y los desastres que trae consigo la langosta volvieron [...] hacia el centro del estado de Oaxaca [...]; inclusive la Secretaría de Fomento remitió algunos ejemplares [de estos insectos] para su estudio al señor Villada, profesor de Historia Natural en este establecimiento. Según parecer de este profesor [...] la especie que se le presenta es la misma que invadió a principios del año pasado el Soconusco, viniendo, según se afirma, de la región alta de Guatemala [...] por último, es de opinión que esta langosta es exactamente la misma especie que causó grandes estragos en nuestros estados del sur y oriente los años de 1854 y 1857 [...] Tratándose, pues, de la reaparición de una plaga que ya otras veces ha azotado cruelmente al país. ${ }^{78}$

Solamente resta decir que aspirar a un conocimiento más completo sobre la naturaleza de estas plagas dependerá de llevar a cabo un análisis que contemple lo acaecido en Guatemala y México durante el siglo XIX, y que preste especial atención en la influencia que tuvieron los factores meteorológicos, las estructuras agrarias y las prácticas agrícolas en la evolución de estos fenómenos naturales.

78 "Informe de la Escuela Nacional de Agricultura sobre la plaga de langosta que afecta el sureste del país (1880)", en Antonio Márquez Delgado, La lucha contra la langosta en México, p. 113. 


\section{BIBLIOGRAFÍA}

Alberola Romá, Armando, "Procesiones, rogativas, conjuros y exorcismos: el campo valenciano ante la plaga de langosta de 1756”, en Revista de Historia Moderna. Anales de la Universidad de Alicante, núm. 21, 2003, 383-410.

Beltrán, Enrique, Lamarck. Interprete de la naturaleza, México, Talleres Gráficos de la Nación, 1945.

Berry, Charles, "La ciudad de Oaxaca en vísperas de la reforma", en Historia Mexicana, vol. xIx, núm. 1, 1969, 23-61.

Bowles, William, Introducción a la historia naturaly a la geografia física de España, Madrid, Imprenta Real, 1782.

Bracamonte y Sosa, Pedro, Amos y sirvientes. Las haciendas de Yucatán, 1789-1860, Mérida, Universidad Autónoma de Yucatán, 1993.

Buj Buj, Antonio, "Control de plagas de langosta y modernización agrícola en la España de la segunda mitad del siglo XIx", en Geo Crítica, Cuadernos críticos de geografia humana, núm. 95, 1992, 1-41. , "La plaga de la langosta. Permanencia de un riesgo biológico milenario", en Scripta Nova. Revista Electrónica de Geografía y Ciencias Sociales, vol. XII, núm. 270, agosto de 2008.

Caminera, John L. et al., Field Guide to Grasshoppers, Katydids, and Crickets, Ithaca, Cornell University Press, 2004.

Campos Goenaga, María Isabel, "Yucatán: entre el privilegio de la Corona y el azote de la naturaleza", en Cuicuilco, vol. 10, núm. 29, septiembre-diciembre, 2003, 1-18.

CANTIMPrÉ, Thomas de, Liber de naura rerum... en Codex Grantensis c-67 (versión digital), Granada, Biblioteca Universitaria de Granada, 2002.

Castañeda Guzmán, Luis, comp., y Manuel Esparza, ed., Cordilleras eclesiásticas de Oaxaca, 1820-1880, México, Instituto Nacional de Antropología e Historia, Carteles Editores, 2002.

Castellanos Cambranes, Julio, Café y campesinos en Guatemala, 1853-1897, Guatemala, Editorial Universitaria, 1983.

Chapman, R. F., The Insects. Structure and Function, Cambridge, Harvard University Press, 1982. 
Chinchilla, Anastasio, Memoria sobre los insectos perjudiciales a la agricultura y medios de destruirles..., Madrid, 1844.

Chinchilla, Perla, "Introducción", en Elías Trabulse, coord., Historia de la ciencia en México. Siglo XIX. La ciencia mexicana del periodo nacional, México, Fondo de Cultura Económica, 1985, 9-25.

Boucias, D. J. y J. C. Pendland, Principles of Insects Pathology, Boston, Kluber Academic Press, 1998.

DAmpf, A., Contribuciones a la morfología y biología de Shistocerca, México, Comisión Científica Exploradora de la Plaga de la Langosta en el estado de Veracruz, 1925.

Díaz del Castillo, Bernal, Historia verdadera de la conquista de la Nueva España..., México, Editorial Porrúa, 1963.

Duvigneaud, Pierre, La synthése écologique, París, Doin, 1984.

Escobar Ohmstede, Antonio, Desastres agrícolas en México. Catálogo histórico. Tomo II. Siglo XIX, México, Ciesas, Fondo de Cultura Económica, 2004.

Fernández de Oviedo, Gonzalo, Historia general y natural de las indias..., vol. II, Madrid, Biblioteca de Autores Españoles, 1959.

Fernández Hernández, Bernabé, "Problemas de la agricultura de Honduras a principios del siglo XIx", en Temas Americanistas, núm. 7, 1990, 23-27.

, El gobierno del intendente Anguiano en Honduras (17961812), Sevilla, Universidad de Sevilla, 1997.

Florescano, Enrique, Precios del maiz y crisis agrícolas en México (1708-1810), México, El Colegio de México, 1969.

Florescano, Enrique y Susan Swan, Breve historia de la sequia en México, Xalapa, Universidad Veracruzana, 1995.

García Acosta, Virginia, América Molina del Villar y Juan Manuel Pérez Zevallos, Desastres agrícolas en México. Catálogo histórico. Tomo I. Época prehispánica y colonial (958-1822), México, Ciesas, Fondo de Cultura Económica, 2003.

García Quintanilla, Alejandra, "Saak y el retorno del fin del mundo. La plaga de langosta en las profecías del Katun 13 Ahau", en Ancient Mesoamerica, vol. 16, núm. 2, 2005, 327-344. 
Gutiérrez Cruz, Sergio Nicolás, “Don Sebastián Esponda y Olaechea, abogado de las Reales Audiencias de México y Guatemala", en Liminar. Estudios Sociales y Humanísticos, vol. 5, núm. 2, 2007, 163-177.

"Vínculos sociales y políticos en el partido de Tuxtla, provincia de Chiapas, en el último cuarto del siglo xvin", en Diálogos. Revista Electrónica de Historia, 2008, 656-666.

Herrera, Sajid Alfredo, "Primary Education in Salvador and Sonsonate, 1750-1808”, en Jordana Dym y Christopher Belaubre, Politics, Economy, and Society in Bourbon Central America, 17591821, Denver, University of Colorado Press, 2006, 1-17.

Ibn Musa Al-Damiri, Muhammad, Hayat al-Hayawan..., en Eugene Daumas, Itineraire d'une caravane du Sahara us Pays des Negres, París, 1848.

Instrucción sobre la plaga de langostas, medios de exterminarla o de disminuir sus efectos y de precaver la escasez de comestibles. Dispuesta de orden del superior gobierno de Guatemala, por el licenciado don José de Valle, abogado de esta Real Audiencia, Guatemala, Impresa por don Ignacio Beteta, 1804.

Jurado Jurado, Juan Carlos, “Terremotos, pestes y calamidades. Del castigo a la misericordia de Dios en la Nueva Granada, siglos XVIII y XIX”, en Procesos Históricos, núm. 5, 2004, 1-35.

León Vegas, Milagros, "Una simiente devastadora del agro antequerano: la plaga de langosta de 1620", en Revista de Historia Moderna, núm. 23, 2005, 285-306.

, Dos siglos de calamidades públicas en Antequera. Crisis epidémicas y desastres naturales (1599-1804), Antequera, Ayuntamiento de Antequera y Fundación Municipal de Cultura, 2007.

Lockwood, Jeffrey, Locust. The Devasting Rise and Mysterious Disappearance of the insect that Shaped the American Frontier, Nueva York, Basic Books, 2004.

Malpica, G. , "La langosta”, en Revista de las plagas del año, MéxiCo, 1912.

Márquez Delgado, Antonio, La lucha contra la langosta en México, México, Editorial Fournier, 1963. 
McCreery, David, Rural Guatemala, 1760-1940, Stanford, Stanford University Press, 1994.

Memoria de la Secretaría de Estado y del despacho de Fomento, Colonización, Industria y Comercio de la República Mexicana escrita por el Ministro de Fomento, C. Manuel Siliceo, para dar cuenta de ella al Soberano Congreso Constitucional, México, Imprenta de Vicente García Torres, 1857.

Memoria que el gobernador del estado presenta al primer congreso constitucional de Oaxaca en sus sesiones ordinarias de 1858, Oaxaca, Imprenta de Ignacio Rincón, 1858.

Metcalf, R. L. y W. H. Luckmann, Introduction to Insect Pest Management, Nueva York, John Wiley, 1982.

Obras completas de Francisco Zarco, vol. IV. Periodismo politico y social 4, México, Centro de Investigación Científica Jorge L. Tamayo, 1990.

Obras completas de Francisco Zarco, vol. v. Periodismo político y social 5, México, Centro de Investigación Científica Jorge L. Tamayo, 1990. Ortega Reyes, Manuel, "La langosta", en Boletin de la Sociedad Mexicana de Geografía y Estadistica, tomo IV, 1857, 147-152.

Pacheco Troconis, José Germán, El añil: historia de un cultivo olvidado en Venezuela, 1767-1870, Tesis doctoral, Universidad Autónoma de Barcelona, Departamento de Economía e Historia Económica, 2000.

PASTOR, Rodolfo, "Introducción”, en Enrique Florescano, comp., Fuentes para la historia de la crisis agrícola de 1785-1786, vol. 1, México, Archivo General de la Nación, 1981, 29-63.

Pelaez Almengor, Óscar Guillermo et al., La ciudad ilustrada: Las influencias del pensamiento ilustrado en el traslado, construcción y organización de la economía de la ciudad de Guatemala, 1776-1821, Informe de Investigación, Universidad de San Carlos de Guatemala, Centro de Estudios Urbanos y Regionales, 2004.

Peniche, Paola, "Los desastres de 1770 en la península y su impacto en el sistema colonial yucateco", en Gabriela Vera Cortés, coord., Devastación y éxodo. Memoria de seminarios sobre desastres en México, México, Ciesas, Sedesol, Conacyt, 2009, 229-246. 
, Tiempos aciagos. Las calamidades y el cambio social del siglo XVIII entre los mayas de Yucatán, México, Ciesas, Miguel Ángel Porrúa, 2010.

QuezadA, Sergio, "Epidemias, plagas y hambres en Yucatán, México (1520-1700)", en Revista Biomed, núm. 6, 1995, 238-242.

Reina, Leticia, "Poblamiento y epidemias en el Istmo de Tehuantepec, siglo xIx", en Desacatos. Revista de Antropología Social, primavera, núm. 1, 1999, 157-175.

Rivas Moreno, F., La plaga de langosta en México, Argelia y otros paises, Madrid, 1888.

Sagrada Biblia (versión directa de las lenguas originales por Eloino Nacar Fuster), Madrid, Editorial Católica, 1947.

SAHAGún, Fray Bernardino de, Historia general de las cosas de Nueva España..., México, Editorial Porrúa, 1990.

SÁnchez DíAz, Gerardo, "Crisis agrícolas y abastecimiento de granos en Michoacán, 1880-1910”, en Gail Mummert, coord., Almacenamiento de productos agropecuarios en México, México, El Colegio de Michoacán, Almacenes Nacionales de Depósito, S. A., 1987, 134-142

Sánchez Silva, Carlos, Indios, comerciantes y burocracia en la Oaxaca poscolonial, 1786-1860, México, Instituto Oaxaqueño de las Culturas, Fondo Estatal para la Cultura y las Artes, Universidad Autónoma Benito Juárez de Oaxaca, 1998.

Sevilla, San Isidoro de, Etimologías, 2 vols., Edición facsimilar, Madrid, Editorial Católica, 1982-1983.

Sistach, Xavier, Bandas, enjambres y devastación. Las plagas de langosta a través de la historia, Barcelona, Almuzara, 2007.

Sorensen, W. Conner, Brethren of the Net. American Entomology, 1840-1880, Tuscaloosa, University of Alabama Press, 1995.

SteEdman, A., ed., Locust Handbook, Londres, Natural Resources Institute, 1990.

Tempsky, Gustav von, Mitla. A narrative of incidents and personal adventures on a journey in Mexico, Guatemala, and Salvador in the years of 1853 to 1855 . With observations on the modes of life in those countries, editado por J. S. Bell, Londres, 1858.

TorT, José María, "Dictamen de la comisión nombrada para abrir el 
dictamen sobre la memoria relativa a la langosta, (1858)", en Boletin de la Sociedad Mexicana de Geografia y Estadistica, tomo vI, 1858, 153-157.

Trabulse, Elías, "La Colonia (1521-1810)”, en Ruy Pérez Tamayo, coord., Historia de la ciencia en México, México, Fondo de Cultura Económica, 2010, 15-42.

Tratado de las langostas muy útil y necesario en que se tratan cosas de provecho y curiosidad para todos los que profesan letras divinas y humanas, y las mayores ciencias, compuesto por el doctor Juan de Quiñones..., Madrid, Luis Sánchez Impresor, 1620.

Uvarov, Boris, "A Revision of the Generous Locusta with a New Theory", en The Bulletin of Entomological Research, vol. XII, 1921, 135-163.

, Locust and Grisshoppers. A Handbook for their Study and Control, Londres, The Imperial Bureau of Entomology, 1928.

FeCha de ReCEPCIÓn DEL ARTículo: 19 de mayo de 2011

FECHA DE ACEPTACIÓN Y RECEPCiÓN DE LA VERSIÓN FINAL: 21 de julio de 2011 